\title{
Fault Geometry at the Rupture Termination of the 1995 Hyogo-ken Nanbu Earthquake
}

\author{
by Haruko Sekiguchi, Kojiro Irikura, and Tomotaka Iwata
}

\begin{abstract}
The source geometry and slip distribution at rupture termination of the 1995 Hyogo-ken Nanbu earthquake were investigated using waveform inversion on the assumption of fault branching in the northeastern part of the rupture model. Possible branching of the Okamoto fault is suggested both by the static-displacement distribution and damage extension east of Kobe (Nishinomiya area). To exclude data contaminated by the basin-edge-diffracted wave in the waveform-inversion process, we examined the spatio-temporal variation of its influence and from a comparison with a flat model, we determined windows appropriate for the data. Three subevents were identified, as was reported in previous works. The largest was in the shallow part on the Awaji side, whereas the smaller two occurred at great depths $(>7 \mathrm{~km})$ on the Kobe side. We found a smaller subevent in the deep part of the branch. Total variance reduction was larger, and the ABIC value was smaller when we assumed the branch than when we did not, which shows the superiority of the branching fault model. Resolution checks showed that the slips on proposed branched portions are physical and not caused by random-data noise or systematic errors in Green's functions that arise from misestimation of velocity structures. Calculation of the relative static displacement between two leveling observation stations near the branching fault also showed the greater utility of the branching fault model. The effect of slip on the branched fault has been shown in near-source ground-motion simulation using the 3D finite-difference method (Iwata et al., 1999). The characteristic distribution of ground motion in the near-source region indicated by the damage distribution is well reproduced by the modeling of both the source process and wave propagation in the realistic 3D velocity structure. Slip on the branched fault affected the ground motion in eastern Kobe (Nada and Higashi-Nada wards), Ashiya, and Nishinomiya cities, but its contribution is not dominant even in those regions; about 30 to $50 \%$ maximum velocity in the frequency range of 0.1 to $1.0 \mathrm{~Hz}$.

We conclude that branching rupture of the Okamoto fault during the Hyogo-ken Nanbu earthquake is the preferable interpretation on the source process of this earthquake. This supports the idea of a geometrical barrier suggested by geological observations.
\end{abstract}

\section{Introduction}

Various aspects of the Hyogo-ken Nanbu (Kobe), Japan, earthquake $\left(M_{\mathrm{JMA}}=7.2,05: 46: 51.5 \mathrm{JST}, 17\right.$ January 1995) has been analyzed by many researchers. The goal has been to answer the haunting question "how was such a huge disaster generated?" In particular, the mechanism that caused the concentrated damage distribution, the so-called damage belt, has been intensively discussed. From analyses of strong-motion data, we have learned that the rupture directivity constituting the source process and the local surface geology, including the basement topography, were important in the generation of strong ground motion in the near-source area. To assess their combined effects, total simulations of near-source ground motions that took into account the rupture process and 3D velocity structure were made (Kawase et al., 1997; Pitarka et al., 1998; Furumura and Koketsu, 1998). Furumura and Koketsu (1998) and Pitarka et al. (1998) simulated near-source ground motion in the complex basin-edge structure using the 3D finite-difference method and the source models of Yoshida et al. (1996) and Sekiguchi et al. (1996b), respectively. They obtained a beltshaped, high-ground-velocity zone similar to the damage belt distribution (Fig. 1), but their highest ground-velocity 


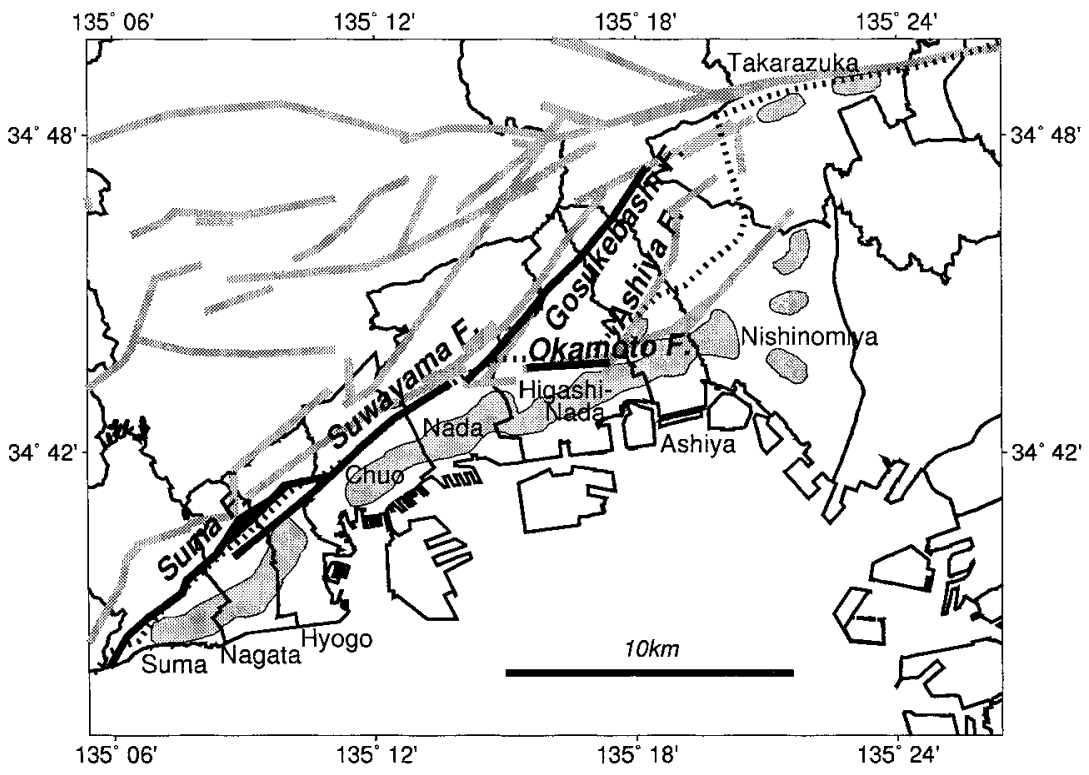

Figure 1. Damage belt in the Kobe area is indicated by light gray zone. The digitized damage belt location data by Koketsu (1998). Black and gray lines show the active fault traces found by Ishihara et al. (1991). The black lines indicate ones estimated to be causative faults in this study. The dashed line shows the boundary of the basin's edge (Iwata et al., 1999). zone stops at the eastern ends of Higashi-Nada Ward, whereas the actual damage belt extends much further to the east.

From Suma to Nada Ward, causative faults estimated from the aftershock hypocenter distribution (Nemoto et al., 1996) run along the basin edge, and the damage belt was formed at about a 1-km offset (Fig. 1). East of Nada Ward, the causative faults estimated from the aftershock distribution have strikes departing from the basin edge. In contrast, the damage belt extends along the basin edge. The Okamoto fault, which begins near the junction of the Suwayama and Gosukebashi faults (active structures considered to be part of the causative fault system) and parallels the edge of the basin east of Nada Ward (Kobe City and Institute of Construction Engineering, 1998), was then suspected to have ruptured. Additional slip on the Okamoto fault was expected to better explain the strong ground motion distribution in Ashiya and Nishinomiya City. The Okamoto fault is beyond the dense aftershock zone, but several aftershocks occurred along it just after the mainshock (Nemoto et al., 1996). Observations of static displacements, the asymmetry of horizontal static-displacement vectors on both sides of the Gosukebashi fault from triangulation observations (Hashimoto et al., 1996), and the irregular fringes on the SAR interferogram around the Okamoto fault (Fig. 2) (Murakami et al., 1995) also support the possibility of slip on the Okamoto fault. Geological observations (e.g., King, 1986; Nakata et al., 1998) have shown that the irregularity of the rupturing surface, such as fault bends and branching, works as a geometric barrier that impedes or terminates rupture extension. Kame and Yamashita (1999) used numerical calculation to study rupture extension without specifying the next rupturing surface. They found that the rupture surface tends to bend after reaching a certain level of rupture-propagation velocity and terminate itself. At a certain rupture-propaga- tion velocity, the surface of the peak shear stress splits in two, and when the rupture was permitted to branch, the branch in the low normal stress area quickly bent and its stretch became short, whereas the other branch in the high normal stress area slowly extended and its stretch became long. This feature closely resembles the configurations of the Suwayama, Gosukebashi and Okamoto faults. The calculation was for virgin rock, but the essential mechanism in which the rupture surface bends and then terminates is thought to be valid even for rupture on a weak zone such as pre-existing faults.

We considered it worthwhile to investigate the possibility of rupture on the Okamoto fault. Koketsu (1998) examined the possibility of slip on the Okamoto fault (designated as part of the Ashiya fault in his article) by comparing waveform inversion results from fault-plane models with and without the Okamoto fault. He concluded that there is some possibility of slip on the Okamoto fault because the variance reduction of the waveform inversion with the Okamoto fault is better than without, but not quantitatively so. We here propose another fault-plane model with a branched segment - the Okamoto fault. At the other end of the fault in this earthquake (the southwest end of the Nojima fault), branching of the surface traces has been observed (Awata and Mizuno, 1998). Observation stations in this area, however, are very few, and it is impossible to examine fault branching at depth using the ground-motion records for this southern end.

To investigate detailed rupture geometry with improved reliability, we gathered a new data set, adding strong-motion records not previously used, and verified all the elements of inversion. This article consists of six parts: (1) fault model, parameterization, and methodology; (2) Data selection and examination of the applicability of a 1D approximation of the $3 \mathrm{D}$ velocity structure to compute synthetic waveforms; 

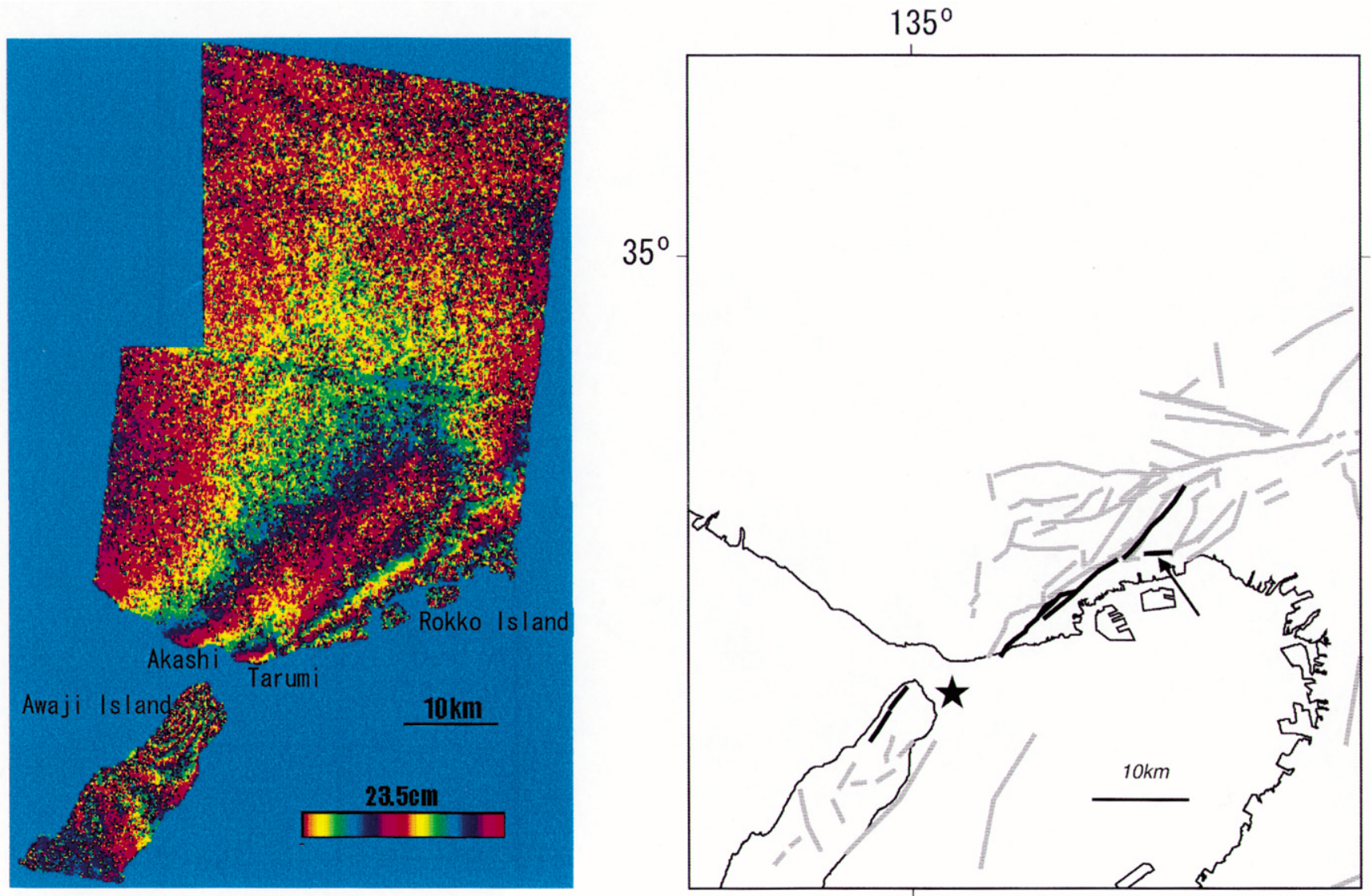

Figure 2. (Left) SAR (Synthetic Aperture Radar) interferogram made by comparing two SAR images before and after the Hyogo-ken Nanbu earthquake (Murakami et al., 1995). Japanese words in the original figure has been translated into English, and several marks added with the author's permission. The detected crustal deformation shown by SAR interferometry represents ground displacements parallel to the satellite line of the site. (right) Active fault systems in the source region of the Hyogo-ken Nanbu earthquake (Ishihara et al., 1991). The scale of this map is the same as that in the left hand side. Dense fringes are present along the main line of the estimated causative faults; the Nojima, Suwayama, Suma, and Gosukebashi faults. Some irregular fringes are present around the surface trace of the Okamoto fault (indicated by the arrow in the right figure). (See Fig. 1 for locations of the named active faults.)

(3) waveform inversion; (4) Examination of the likehood of the inversion result using numerical resolution tests; (5) contribution of the branching fault to static displacement, and (6) contribution of the branching fault to near-source ground motion.

\section{Fault Model, Parameterization, and Inversion Methodology}

\section{Fault Model}

A new fault plane model is proposed (Fig. 3, Table 1). The main part of the fault model is located taking into account the results of many detailed studies done after the earthquake: the relocated mainshock and aftershock hypocenters reported by Nemoto et al. $(1996,1997)$, the static displacements of triangulation points of Hashimoto et al. (1996), the geodetic inversion results of Ozawa et al. (1997), and the constraints on the location of the intersection of the causative fault planes and the earth surface in the Kobe City area obtained by Sekiguchi et al. (1996a,b). The fault model is divided into four main segments, A, B, C, and D (respectively corresponding to the Nojima, Suma, Suwayama, and Gosukebashi faults), and a branch segment, E, corresponding to the Okamoto fault. We performed the waveform inversion with $\mathrm{ABCDD}^{\prime}$ in order to examine the effect of segment $\mathrm{E}$ on the inversion results. Segment $\mathrm{D}^{\prime}$ was introduced to keep the same number of parameters in the waveform inversions with the two different fault models.

\section{Representation and Discretization of Faulting}

Faulting is represented as moment-release vectors on planar surfaces. According to Aki and Richards (1980), the observation equation of ground motion at position $\boldsymbol{x}$ due to a displacement discontinuity across the faulting surface, $\Sigma$, is 


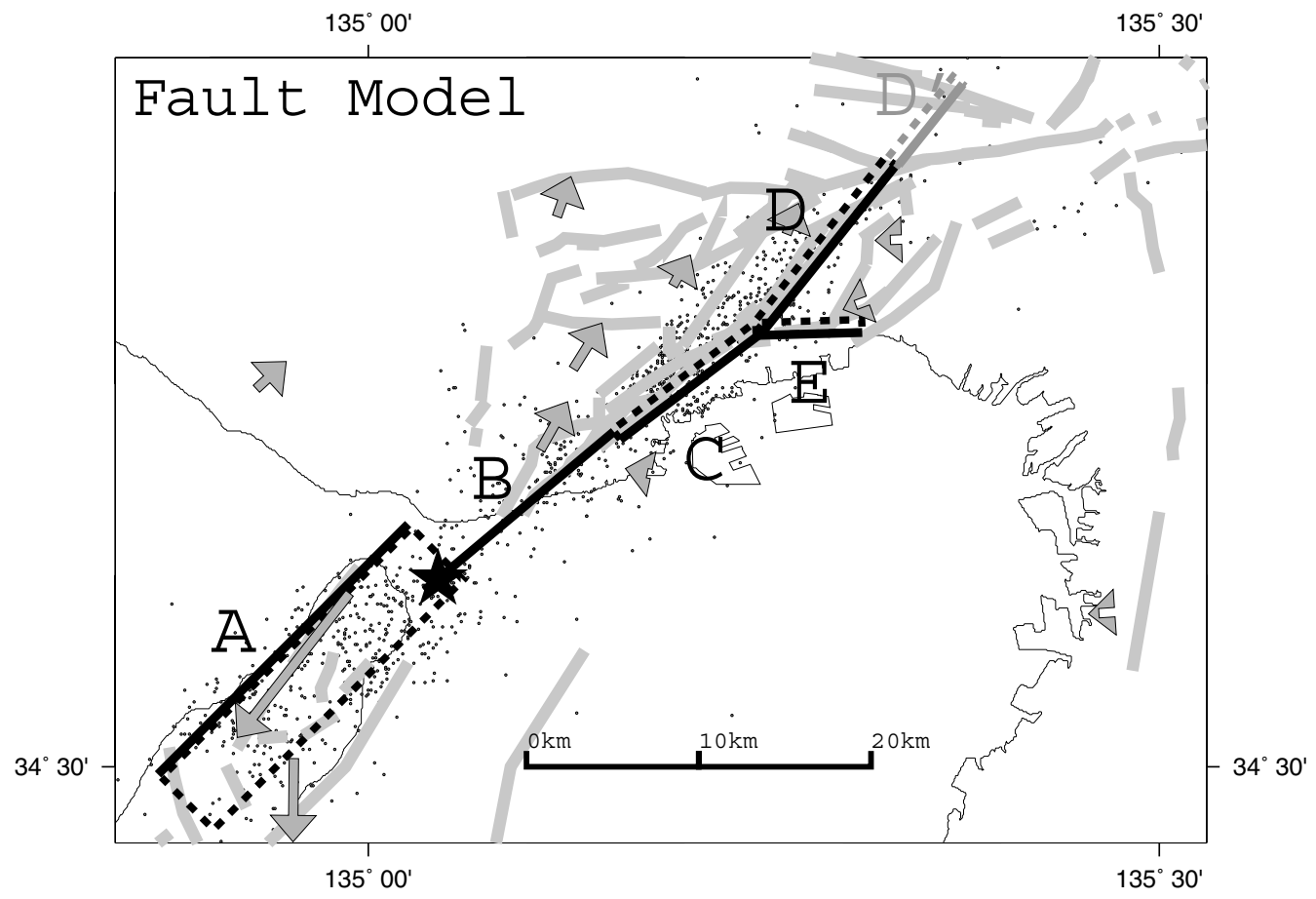

Figure 3. Fault-plane model (with segments A, B, C, D, and E). Black and gray lines show the active-fault traces reported by Ishihara et al. (1991). The black lines are those estimated to be causative faults in this study. Vectors show static displacements during 1984 and 1995 after the earthquake, as determined by Hashimoto et al. (1996) from GPS data. Epicenters of the mainshock and aftershocks during the day of the mainshock are those determined by Nemoto et al. $(1996,1997)$. Dots are epicenters of aftershocks that occurred within 18 hours after the mainshock. The fault plane model with segments $\mathrm{A}, \mathrm{B}, \mathrm{C}, \mathrm{D}$, and $\mathrm{D}^{\prime}$ was the reference model used to examine the effect of segment $\mathrm{E}$.

Table 1

Fault Model Parameters

\begin{tabular}{ccccc}
\hline Segment & Corresponding Active Fault & Strike (deg) & Dip (deg) & Length $(\mathrm{km})$ \\
\hline A & Nojima & 45.0 & 78.0 & 20.5 \\
B & Suma & 50.0 & 90.0 & 14.35 \\
C & Suwayama & 233.0 & 82.0 & 10.25 \\
D & Gosukebashi & 218.0 & 82.0 & 12.3 \\
E & Okamoto & 268.0 & 82.0 & 6.15 \\
\hline
\end{tabular}

$$
\dot{u}_{n}(\mathbf{x}, t)=\iint_{\Sigma} m_{p q}(\xi, \tau)^{*} \dot{G}_{n p, q}(\mathbf{x}, t ; \xi, \tau) d \Sigma
$$

with

$$
m_{p q} \equiv\left[u_{i}\right] v_{j} c_{i j p q}
$$

where $m_{p q}$ is the moment-density tensor corresponding to the slip distribution $\left[u_{i}\right] ; G_{n p, q}(\mathbf{x}, t ; \chi, \tau)$ is the spatial derivative of Green's tensor expressing the $n$th component of the displacement response at point $\mathbf{x}$ to a point dislocation in the $p$-direction on a plane normal to the $q$-direction at position $\chi ; v$ is the vector normal to $\Sigma$; and $c_{i j p q}$ is the elastic constant tensor of Hooke's law. A dot denotes differentiation in time. To obtain the spatio-temporal rupture history $\left(m_{p q}\right.$ in right side of equation 1), we numerically inverted the groundmotion data (left side of equation 1) using the multitime window linear-waveform-inversion procedure of Hartzell and Heaton (1983) in which the moment-release distribution is discretized both in space and time. Discretization of the moment release in time is obtained by putting a finite number of temporally localized basis functions $\varphi(t)$ at certain time intervals. We adopted the smoothed ramp function as the basis function. Discretization in space was done by dividing the model fault planes into small subfaults. Arbitrary-directed moment release on the fault plane model was realized by combining two orthonormal unit vectors. Convolution of the unit moment function, $\varphi(t)$, with the temporal and spatial derivative of Green's function representing the jth component of the synthetic-velocity waveform from the $i$ th direction of the moment release on the $l$ th subfault, $g_{j i l}\left(\mathbf{x}, t_{0}+\right.$ $h \Delta t, l, \tau)$, gave a matrix, $\mathbf{A}$, of element waveforms,

$$
\begin{aligned}
\mathbf{A}_{m n}= & \int_{+} g_{j i l}\left(\mathbf{x}, t_{0}\right. \\
& +h \Delta t ; l, \tau)^{*} \varphi\left(\tau-(k-1) \Delta t w+\operatorname{trup}_{l}\right) d \tau
\end{aligned}
$$

with 


$$
\begin{aligned}
& m=\sum_{j}^{J-1} H_{j}+(h-1), \\
& n=(k-1) I L+(i-1) L+1, \\
& \quad(i=1, \ldots I, k=1, \ldots, K, l=1, \ldots, L)
\end{aligned}
$$

where $t_{0}$ is the initial time in the time range of the data used for analysis; $t_{0}+h \Delta t$ refers to discretized time with the increment $\Delta t$; $\operatorname{trup}_{l}$ is the time the rupture front arrives at the $l$ th subfault; and $\Delta t w$ the interval between adjacent time windows. $I, J, K, L$, and $H_{j}$ respectively are the total number of moment release directions, data components, basis functions, subfaults, and data points of the $j$ th component. The problem is determining which weights should be assigned to each element slip discretized into space, time, and two slip directions.

The discretized observation equation in vector form becomes

$$
\mathbf{d}=\mathrm{Am}
$$

where $\mathbf{d}$ is the observation velocity data vector and $\mathbf{m}$ the model parameter vector. Observation equations in the same form as equation (4) with the same discretized source representation can be constructed for other sites. Combining these sets for sufficient number and azimuthal coverage of observation stations gives a large, overdetermined, and simultaneous equation system.

How to choose subfault size is a problem for which no clear criteria have been established. To extract detailed information on the source process, it is preferable to take the smallest possible subfaults, but spatial changes finer than the smallest wavelength for analysis within a certain frequency range cannot be constrained by data. On the other hand, the spatial periodicity arising from discretization of the fault is likely to generate spurious synthetic waves predominant in the corresponding frequency. We therefore set the pointsource intervals such that the dominant frequency caused by the spatial periodicity was well outside the frequency range of our analysis.

We put point-source grids on the fault segment planes at $2.05 \mathrm{~km}$ intervals, and the expected predominant frequency became slightly higher than the frequency range of the present study; $0.1-1.0 \mathrm{~Hz}$. The number of subfaults $(L)$ turned out to be 310 . The moment-release time history was modeled using six time windows $(K)$, each $0.5 \mathrm{sec}$ apart. The slip in each time window was represented by a smoothed ramp function with an $0.8 \mathrm{sec}$ rise time in pure strike and pure dipping directions $(l=2)$. Rupture velocity was fixed at $3.1 \mathrm{~km} / \mathrm{sec}$ for the first time window. Data of three components data $(J=3)$ were used when possible, but one of the components was not available at several stations.

\section{Constraints}

Although the discretized observation (equation 4) is an overdetermined system (after combining equations for a suf-

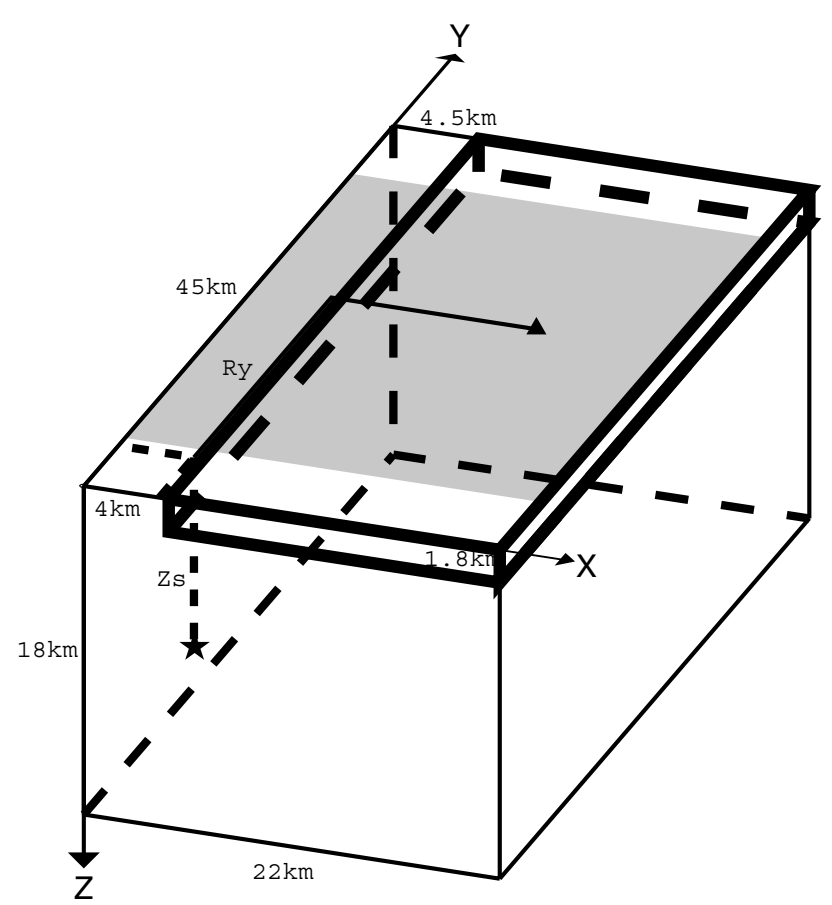

Figure 4. Model space for the 3D FDM wavefield simulation to investigate applicability of the 1D approximation of the 3D velocity structure. Part of a basin is modeled, and its edge is along the Y-axis. The thickness of the sediments is $1.8 \mathrm{~km}$, a typical value estimated along the shoreline in the Kobe area. The point source is located $0.5 \mathrm{~km}$ from the edge of the hard rock region at a certain depth $\left(\mathrm{Z}_{\mathrm{s}}\right) . \mathrm{R}_{\mathrm{y}}$ is the distance from the source to a site on the $\mathrm{Y}$-axis. Waveforms were calculated over the shaded area. Simulation also was done with a flat layer model that had a flat sediment layer with the same thickness and material parameters.

Table 2

Model Parameters of an Underground Structure for Simulation of Basin-Edge-Diffracted Waves

\begin{tabular}{lcccccc}
\hline & $\begin{array}{c}V_{\mathrm{P}} \\
(\mathrm{km} / \mathrm{sec})\end{array}$ & $\begin{array}{c}V_{\mathrm{S}} \\
(\mathrm{km} / \mathrm{sec})\end{array}$ & $\begin{array}{c}\rho \\
\left(\mathrm{g} / \mathrm{cm}^{3}\right)\end{array}$ & $Q_{\mathrm{P}}=Q_{\mathrm{S}}$ & \multicolumn{1}{c}{ Depth $(\mathrm{km})$} \\
\hline Sediment 1 & 2.0 & 0.6 & 2.1 & 80 & 0.85 (inside basin) \\
Sediment 2 & 2.2 & 1.1 & 2.1 & 80 & 1.8 (inside basin) \\
1st rock & 5.5 & 3.2 & 2.4 & 300 & 4.0 & \\
2nd rock & 6.0 & 3.5 & 2.7 & 400 & 17.8 & \\
Half space & 6.7 & 3.9 & 2.8 & 500 & & - \\
\hline
\end{tabular}

ficient number of observation stations), the solution is unstable because the system includes underdetermined model parameters. Stabilization techniques therefore are necessary. Non-negative constraints to limit the rake-angle variation are required to suppress destructive interferences between adjacent subfaults. The non-negative least-squares problem is solved by using the routine NNLS of Lawson and Hanson (1974). 
$R y=12 \mathrm{~km}$

FN
FP
Basin-edge Structure

Flat Layer Structure

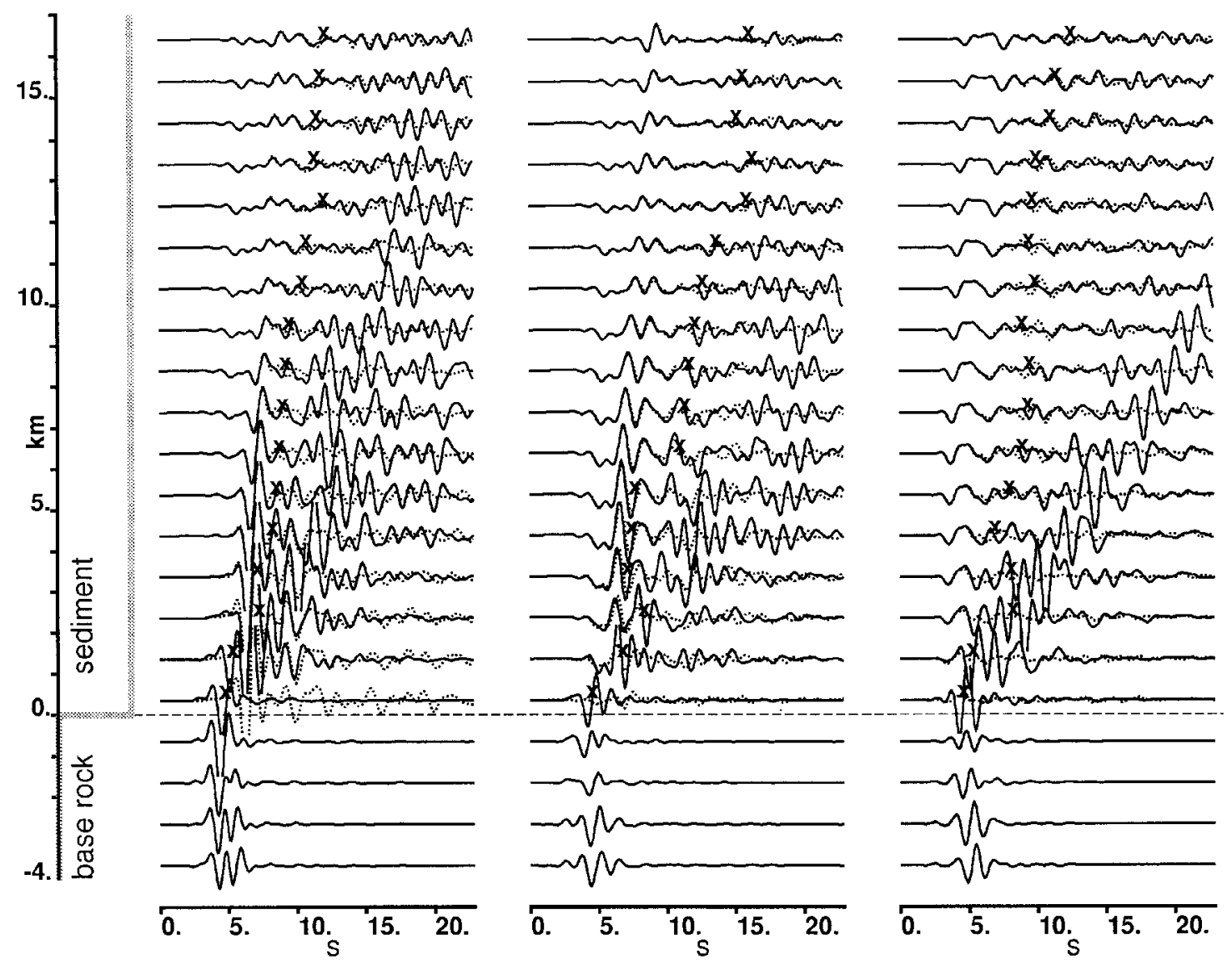

Figure 5. Waveforms generated from a source at $Z_{s}=10 \mathrm{~km}$ deep for the sites $R_{y}$ $=12 \mathrm{~km}$ in the model space shown in Fig. 4. Solid lines are synthetic waveforms for the basin-edge structure, dotted lines for the flat layer structure. FN and FP correspond to the $\mathrm{X}$ - and $\mathrm{Y}$-axis directions in Fig. 4. Crosses (x) indicate the times at which the difference in the two waveforms exceeds $20 \%$ of the maximum amplitude of the two traces. The vertical measure shows the distance from the basin's edge to the sites.

Smoothing constraint is assigned to reduce instability or too much complexity beyond the resolvability of the data based on inspection that slips close together in space and in time should be similar. Different measures of roughness have been proposed to smooth-model parameters, most of which are based on the first and second derivatives of the model parameters with respect to spatial or temporal coordinates. Here, we propose the following smoothing constraints.

We assign smoothing to every pair of unknown parameters $n$ and $n^{\prime}$ whose subfaults are in the same segment with strength normal to the inverse of the spatio-temporal distance between them;

$$
\begin{aligned}
r_{n n^{\prime}}=\|\left\{\operatorname{trup}_{l}-\right. & \operatorname{trup}_{l^{\prime}} \\
& \left.+\left(k-k^{\prime}\right) \Delta t w\right\} V_{s}\|+\| r \text { space }_{l l^{\prime}} \|,
\end{aligned}
$$

where $|*|$ means the first norm. We gather the smoothing equations related to a given model parameter. The smoothing equation for the $n$th parameter is

$$
\left\{\begin{array}{l}
\sum_{n^{\prime}} \frac{1}{r_{n n^{\prime}}} \\
r_{n n^{\prime}} \leq \frac{V_{s}}{f_{h}}
\end{array}\right\} m_{n}-\begin{gathered}
\sum_{n^{\prime}} \frac{1}{r_{n n^{\prime}}} m_{n^{\prime}}=0, \\
r_{n n^{\prime}} \leq \frac{V_{s}}{f_{h}}
\end{gathered}
$$

where rspace $_{l l^{\prime}}$ is the distance between the $l$ th and $l^{\prime}$ th subfaults in space, $V_{s}$ the $S$-wave velocity at $l$ th subfaults, and $n^{\prime}=\left(k^{\prime}-l\right) I L+\left(i^{\prime}-l\right) L+l^{\prime}$. The distance that smoothing reaches should be limited to the length traveled by the $S$ wave in the period corresponding to the high frequency limit $\left(f_{h}\right)$ of the analysis.

A smoothing matrix, $\mathbf{S}$, is constructed by combining 
Hypo_dist. $=17$ km

FN

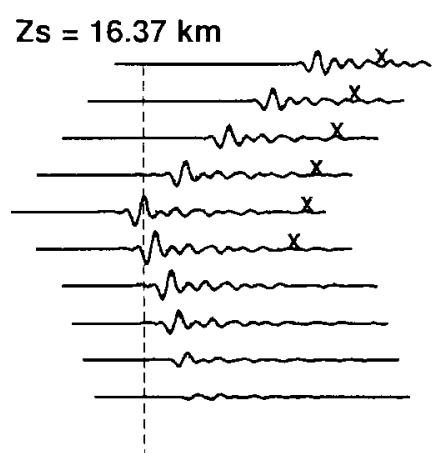

$\mathrm{Zs}=10 \mathrm{~km}$

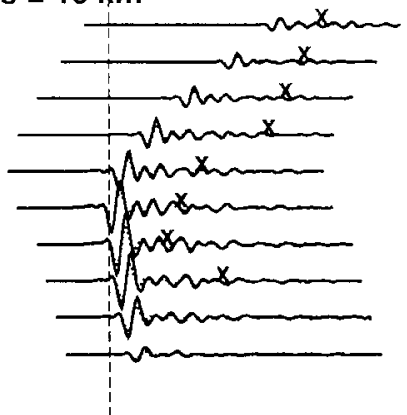

$Z s=5 \mathrm{~km}$

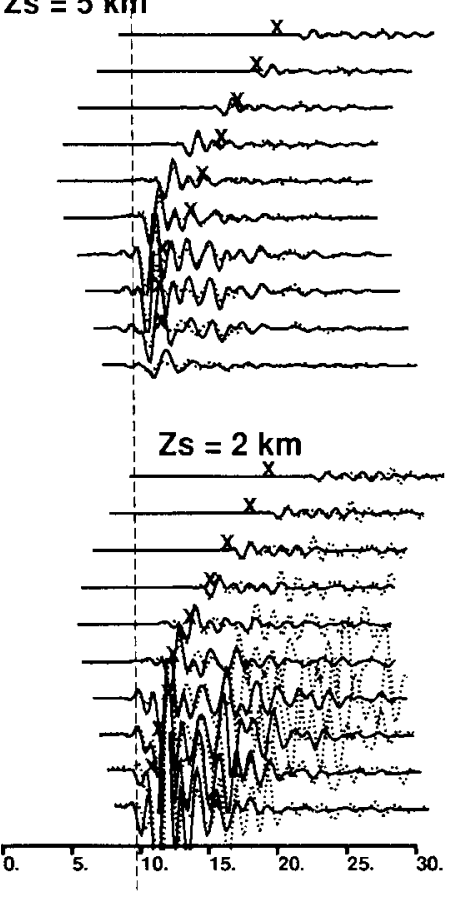

FP

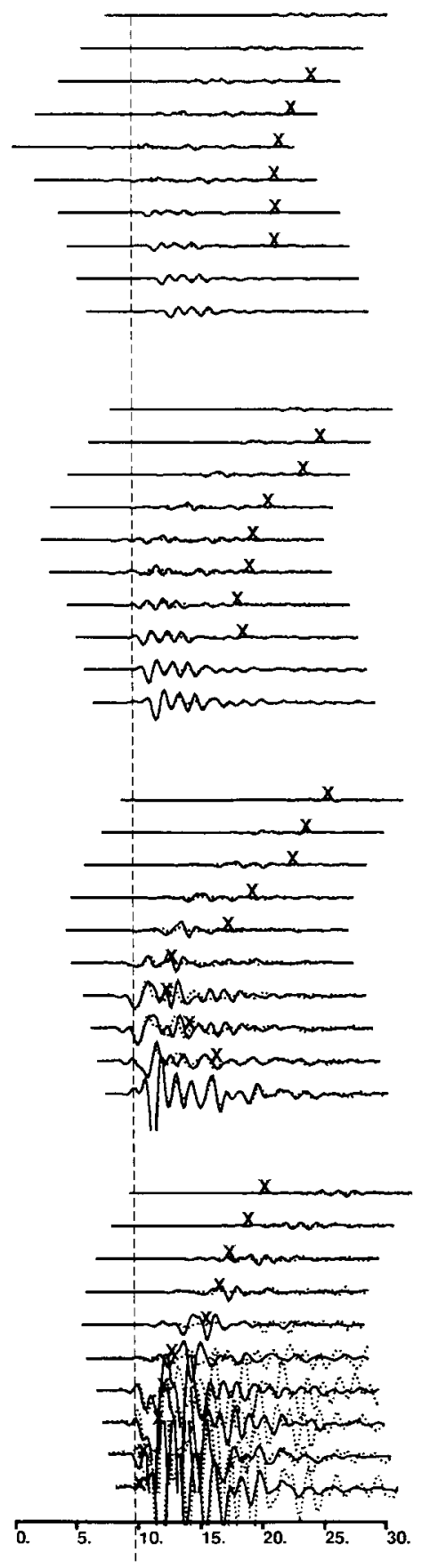

Basin-edge Structure

Flat Layer Structure

UD

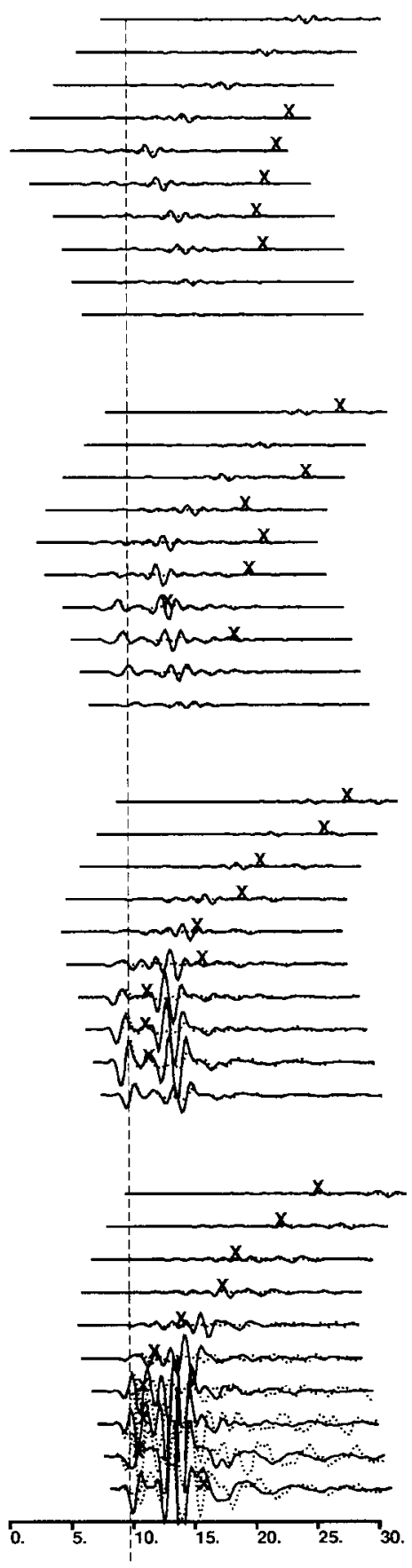

Figure 6. Supposing a certain position inside the basin at a certain location against the Hyogo-ken Nanbu earthquake (i.e., the distance from the basin's edge and the hypocenter distance), all the waveforms calculated in the 3D FD model space (Fig. 4) at that constant basin-edge-distance (5km in this figure) were gathered and plotted taking into account the time shifts corresponding to the rupture propagation from the hypocenter to the sources. The time when the 1-D approximates of the 3-D velocity structure near the basin edge can be estimated (before the time denoted by the dashed lines). The rupture velocity assumed here is $3.1 \mathrm{~km} / \mathrm{sec}$, the same as that assumed in the waveform inversion. 


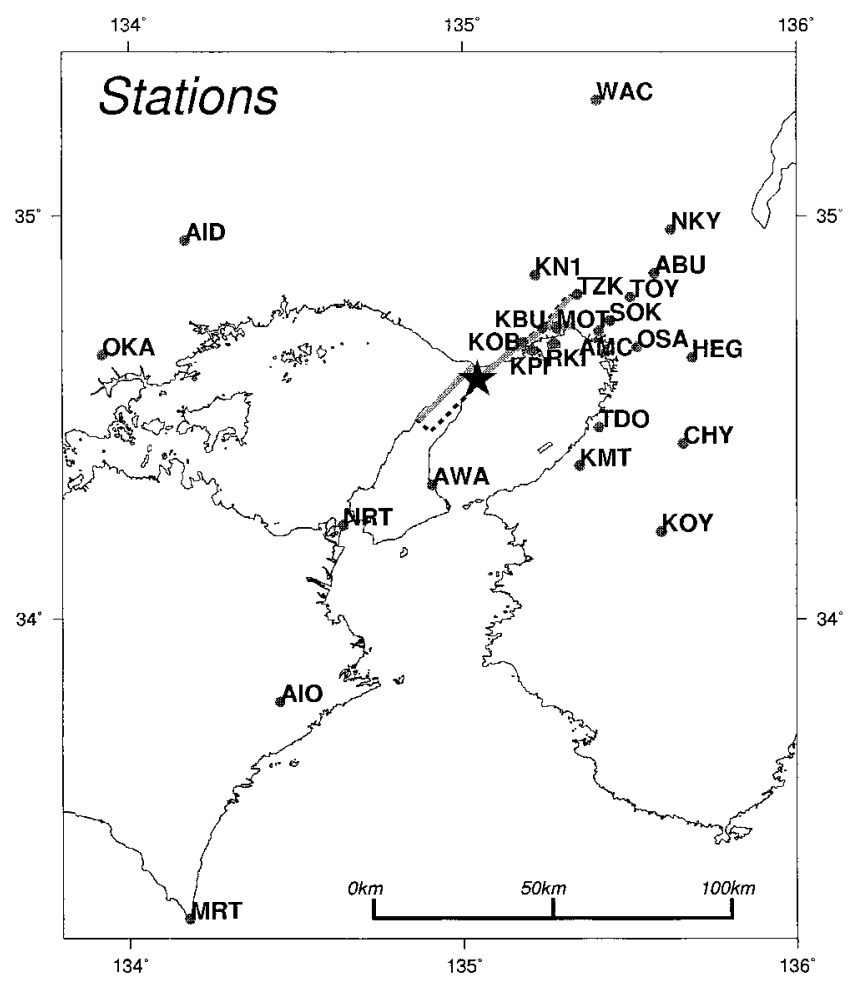

Figure 7. The 25 stations used in the waveform inversion. The collection agency for each record is listed in Table 3.

Table 3

Observed Seismograms Used

\begin{tabular}{llll}
\hline Station & Latitude & Longitude & \multicolumn{1}{c}{ Organization } \\
\hline AMC & 34.7180 & 135.4080 & CEORKA \\
CHY & 34.4390 & 135.6590 & CEORKA \\
KBU & 34.7250 & 135.2400 & CEORKA \\
MOT & 34.7250 & 135.2810 & CEORKA \\
TDO & 34.4800 & 135.4080 & CEORKA \\
TOY & 34.8010 & 135.5010 & CEORKA \\
AID & 34.940 & 134.168 & JMA \\
AIO & 33.792 & 134.452 & JMA \\
AWA & 34.336 & 134.908 & JMA \\
HEG & 34.653 & 135.685 & JMA \\
KOB & 34.69 & 135.18 & JMA \\
KOY & 34.218 & 135.593 & JMA \\
MRT & 33.2483 & 134.1800 & JMA \\
OKA & 34.6583 & 133.9183 & JMA \\
OSA & 34.6783 & 135.5217 & JMA \\
WAC & 35.283 & 135.402 & JMA \\
NKY & 34.9667 & 135.6222 & Kansai Electric Power Co. Inc. \\
SOK & 34.7431 & 135.4417 & Kansai Electric Power Co. Inc. \\
KMT & 34.383 & 135.35 & RRI, Kyoto Univ. \\
ABU & 34.8600 & 135.5735 & RCEP DPRI, Kyoto Univ. \\
KN1 & 34.855 & 135.217 & Matsumuragumi Co. Inc. \\
NRT & 34.234 & 134.641 & Honshu-Shikoku Bridge Public \\
& & & Corporation \\
TZK & 34.8083 & 135.3437 & Railway Technical Research \\
& & & Institute \\
RKI & 34.6883 & 135.2728 & Sekisui House Co. Inc. \\
KPI & 34.670 & 135.208 & Kobe City \\
\hline
\end{tabular}

equation 6 for all the model parameters. The system under scrutiny then becomes

$$
\left[\begin{array}{l}
\mathbf{A} \\
\lambda \mathbf{S}
\end{array}\right] \mathbf{m}=\left[\begin{array}{l}
\mathbf{d} \\
0
\end{array}\right]
$$

where $\lambda$ is a parameter to control the strength of the smoothing.

\section{ABIC for Selecting Appropriate Smoothing Strength}

When a smoothing constraint is used, the resulting inversion solution depends on the value of $\lambda$, the trade-off parameter controlling the strength of the smoothing constraint. The smaller $\lambda$ becomes, the better the fit between the observed and synthesized waveforms. The moment release distribution, however, is too complicated because of overinterpretation of the data, and the solution is unstable due to noise in the data and/or synthetic Green's functions. To determine the proper value of $\lambda$, we used Akaike's Bayesian information criterion (ABIC) (Akaike, 1980). Yoshida (1989) and Ide et al. (1996) introduced ABIC into source modeling.

When the above system (equation 7) is solved using the least-square-inversion method, Gaussian distributions of error are automatically assumed for synthetic data and estimated parameters, and likehood functions are assumed;

$$
P(\mathbf{d} \mid \mathbf{m}, \sigma)=\left(2 \pi \sigma^{2}\right)^{-\frac{M}{2}} \exp \left[-\frac{\|\mathbf{d}-\mathbf{G m}\|^{2}}{2 \sigma^{2}}\right]
$$

for data distribution, and

$$
P\left(\mathbf{m}, \sigma^{\prime}\right)=\left(2 \pi \sigma^{\prime 2}\right)^{-\frac{M_{s}}{2}} \exp \left[-\frac{\|\mathbf{S} \mathbf{m}\|^{2}}{2 \sigma^{\prime 2}}\right]
$$

for prior distribution of the parameters, that is, smooth distribution of slip in space and in time is given as a priori information for the parameter distribution. $M$ and $M_{s}$, respectively, are number of data and the smoothing equations. The ratio $\sigma / \sigma^{\prime}$ turns out to be $\lambda$. Based on the idea of ABIC, a set of parameters that have the largest values in the integration of the product of the above two distributions with respect to the model parameter gives the largest entropy, and realization of such parameter set should occur most frequently extracting the largest amount of information included in the simultaneous equations. The ABIC value is defined as follows (Akaike, 1980):

$$
\begin{aligned}
A B I C & =-2 \log \left|\int P(\mathbf{d} \mid \mathbf{m}, \sigma) P\left(\mathbf{m}, \sigma^{\prime}\right) d \mathbf{m}\right|+2 N_{h p} \\
& =\left(M+M_{s}-N\right) \log 2 \pi+\left(M+M_{s}-N\right) \\
& \log \left(\|\mathbf{d}-\mathbf{A} \mathbf{m}\|^{2}+\lambda^{2}\|\mathbf{S} \mathbf{m}\|^{2}\right)-2 M_{s} \log \lambda \\
& +2\left(M+M_{s}-N\right) \log \left(M+M_{s}-N\right) \\
& +\log \left\|\mathbf{A}^{T} \mathbf{A}+\lambda^{2} S^{T} S\right\|+\left(M+M_{s}-N\right)+2 N_{h p}
\end{aligned}
$$



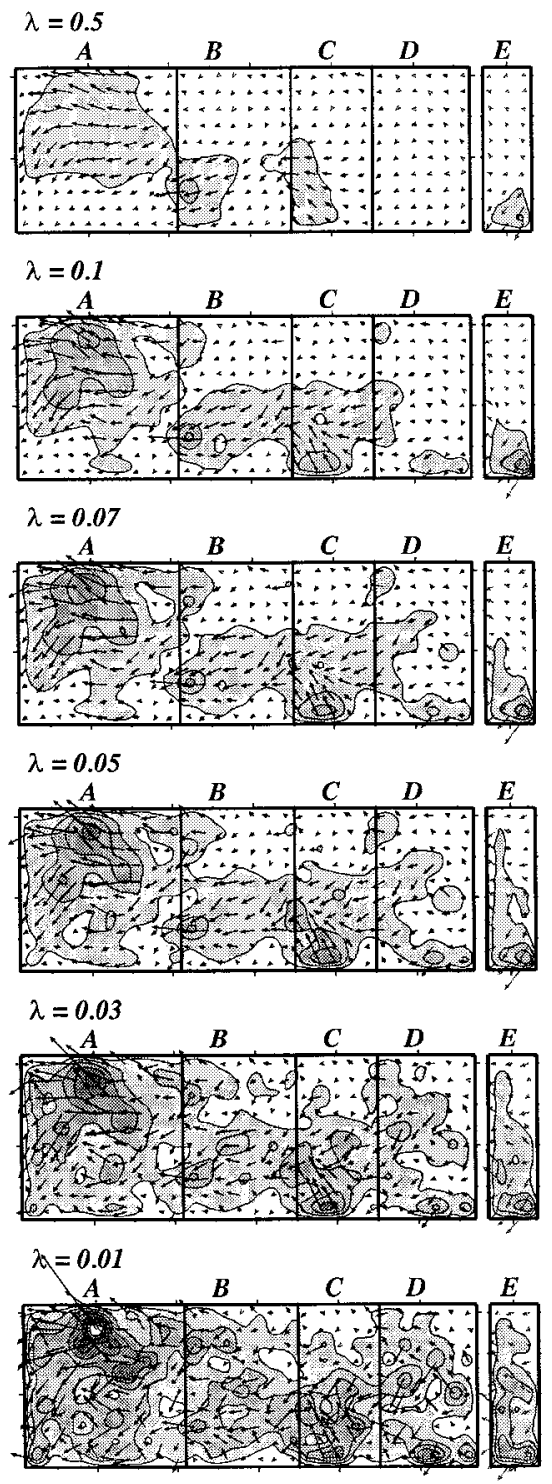
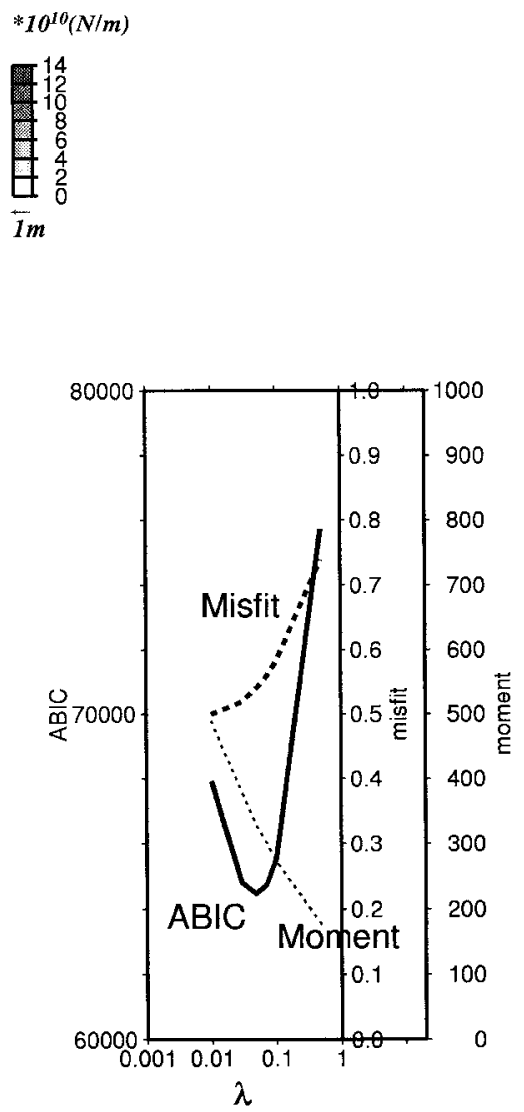

Figure 8. (left) Six different inversion results found with the same fault model, data set, Green's functions, and rake angle variation constraints, and with different smoothing strengths. (right) Variation in ABIC, misfit, and total moment due to the smoothing constraint strength, $\lambda$. where $N$ is the total number of model parameters, $N_{h p}$ the number of hyperparameters; 2 ( $\sigma$ and $\lambda$ or $\sigma^{\prime}$ ) in our system.

A solution is most appropriate in our system when the ABIC value is smallest. The ABIC value depends on unknown parameters $\{\mathbf{m}\}$ and the strength parameter of smoothing, $\lambda$. This value can be calculated only after an inversion result has been obtained. Several waveform inversions with different smoothing strengths, $\lambda$, are performed and the ABIC value for each inversion calculated to find the best parameters set and smoothing strength.

\section{Examination of the 1-D Approximation for the 3-D Velocity Structure and Data Selection}

To obtain improved resolution in the rupture distribution, we used near-source seismograms recorded in the Osaka sedimentary basin. As has been pointed out, the waveforms there, especially in the Kobe City area, are strongly affected by diffraction from the northern edge of the Osaka basin (Kawase 1996; Motosaka and Nagano, 1996; Pitarka et al., 1998). The synthetics used in the waveform inversion, however, are calculated on the assumption of a flat layeredvelocity structure because of computational limitations and the lack of detailed underground structure information. Because the basin-edge-diffracted wave produces a remarkable phase, use of records affected by the basin-edge wave may lead to a wrong slip distribution. Expected errors in the synthetics must be evaluated when the $3 \mathrm{D}$ structure is approximated using the 1D (flat layer) structure in this area to avoid including them in the waveform inversion.

The effect of the basin edge-diffracted wave differs depending on hypocenter depth and the relative location of the site with respect to the source. To gauge spatial variation in its effect, we simulated the wave field in this 3D model space (Fig. 4, Table 2) using the 3D finite-difference method (Pitarka et al., 1998). Figure 5 shows the synthesized wave- 


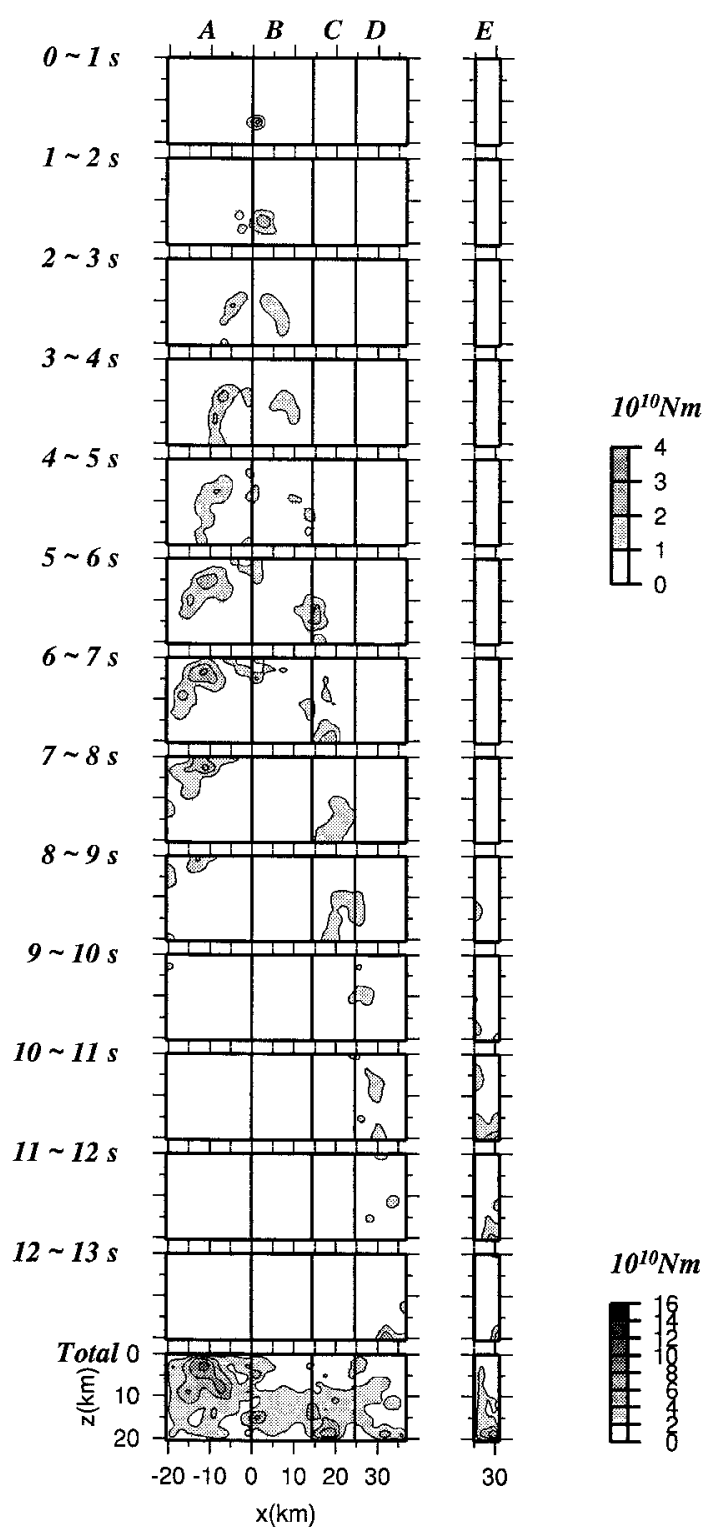

Figure 9. Time progression of rupture in terms of the moment release density at $1 \mathrm{sec}$ intervals.

forms at stations $R_{y}=12 \mathrm{~km}$ from the source at $Z_{\mathrm{s}}=10 \mathrm{~km}$ depth. Solid lines correspond to the basin-edge-structure model, and dashed lines correspond to the flat layered model. Crosses (x) in each seismogram indicate times when the difference in the two waveforms exceeds $20 \%$ of the maximum amplitude of both traces. These differences are caused by the basin-edge-diffracted waves that propagate at a lower velocity than the apparent velocity of the $\operatorname{direct} S$ wave. They affect therefore the direct $S$-wave portion in the near-edge area but separate clearly from it in the off-edge area. Figure 6 shows synthesized waveforms from sources in various $R_{y}$ and $Z_{\mathrm{s}}$ for a site $5 \mathrm{~km}$ from the edge of the basin.

We found that (1) more than $10 \mathrm{~km}$ from the basin's edge, the entire direct $S$-wave portion escapes being overlapped by the basin-edge-diffracted wave; (2) most records in the Kobe downtown area (inside of the basin in the Kobe City) are strongly affected almost from the beginning of the $S$ wave; (3) the KPI and RKI (Figure 7) waveforms, however, are not contaminated by the diffracted wave for the first few seconds after the $S$ arrival; (4) at the KOB and MOT stations, several hundred meters from the basin edge, the basin-edge-diffracted wave is not yet expected to have developed as clearly shown in Figure 5, and Moya and Irikura (1998) showed that the site response in the low-frequency range $(<1 \mathrm{~Hz})$ at MOT is similar to that of a hard rock site, although more than a $700 \mathrm{~m}$ depth of alluvium layer is estimated there from reflection survey analysis (e.g., Huzita, 1996).

\section{Data Selection}

This earthquake provided much strong ground motion data in the source region, particularly east of the hypocenter. The quality and quantity of this waveform data excels those of other earthquakes. The plentitude of valuable data made it possible to investigate complex-fault configuration.

For the simple examination of the 1D approximation for the 3D velocity structure, we selected 25 records (Fig. 7 and Table 3), most being within the epicentral distance of 100 $\mathrm{km}$. The original seismograms at stations KBU and MOT were clipped on some components. Kagawa et al. (1996) restored these seismograms on the basis of the saturation characteristics of servovelocity-type seismographs.

\section{Velocity Structure Models}

Velocity structure modeling was done as follows. Starting models of the underground-velocity structure first were constructed based on geological information obtained from reflection or refraction surveys and from logging records. The parameters of the underground structures then were tuned by trial-and-error to explain the $P$ - and $S$-wave travel times for the mainshock and specific phases in the aftershocks.

Models for sites inside the Osaka basin were based on the results of extensive reflection surveys (e.g., Huzita, 1996) made after this earthquake to determine the depth of bedrock near the basin's edge in Kobe. Velocities and densities of the sedimentary layers were modeled according to Kagawa et al. (1993). Structures of the rock sites at the KOB and MOT stations were assumed.

\section{Green's Functions}

The discrete-wavenumber method (Bouchon, 1981) together with the reflection-transmission method (Kennett and Kerry, 1979) was used to calculate the point-source Green's functions in laterally homogeneous (1D) velocity structures. Velocity synthetics were calculated. The observed records were integrated into velocity when the original records were in acceleration. All the observed and point source synthetics were bandpass filtered from 0.1 to $1.0 \mathrm{~Hz}$ and resampled at $5.0 \mathrm{~Hz}$. 
WAC

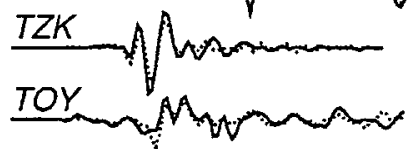

TDO manM M

SOK A ANA Ana

$R K I+A$

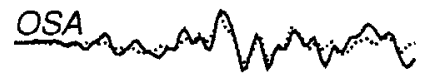

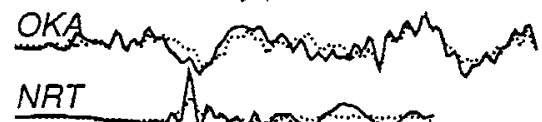
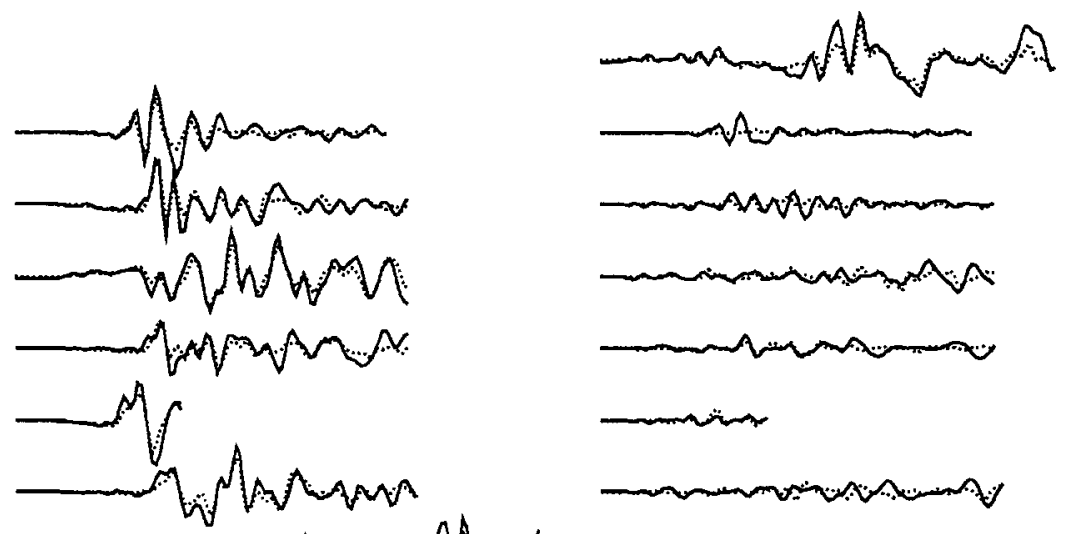

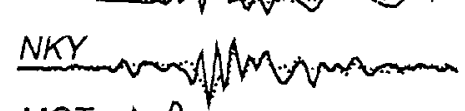

MOT A. Almmanm

KOY

KOB HANAm

KN1 Aforomanam

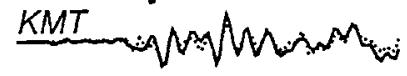

KBU ANANommmem

HEGA $N A$ ton $N A$

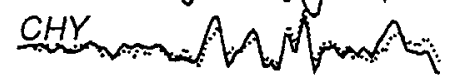

AWA NANAvomin.

AMC NAMANAn

AIO
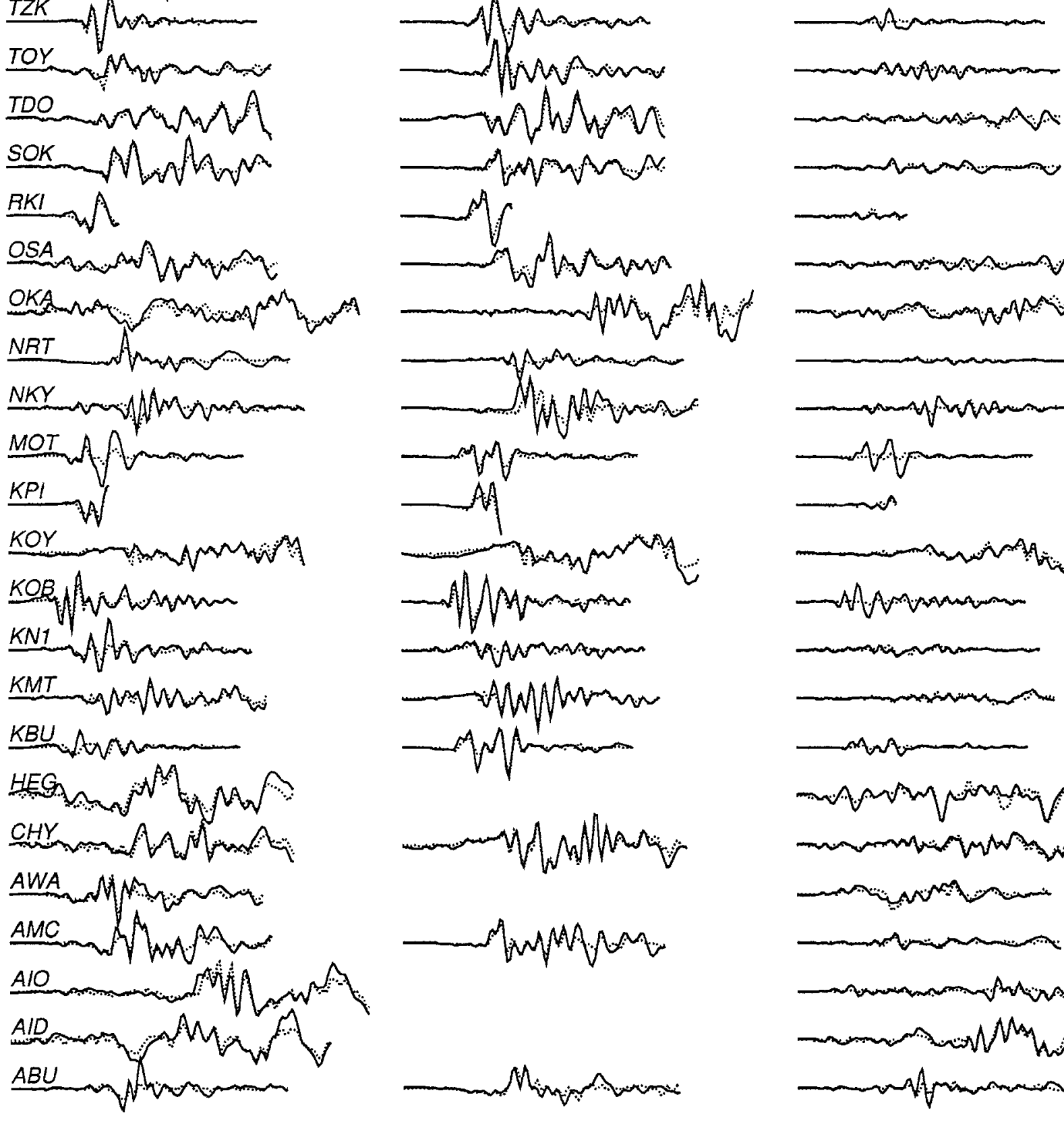

.
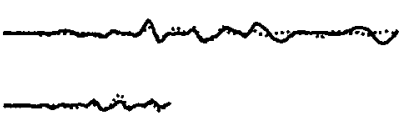

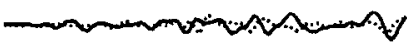
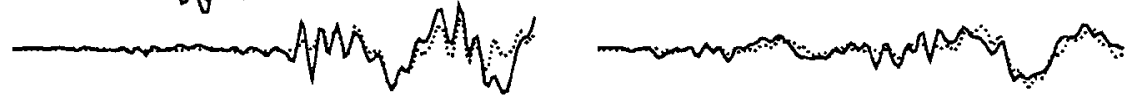

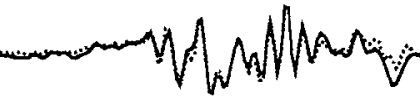

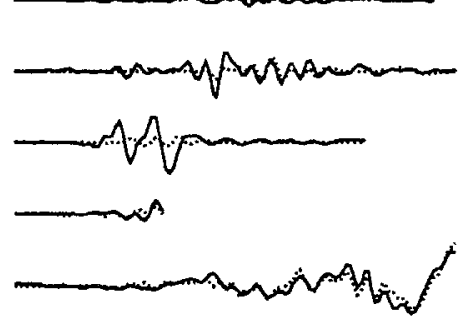

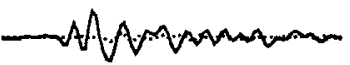
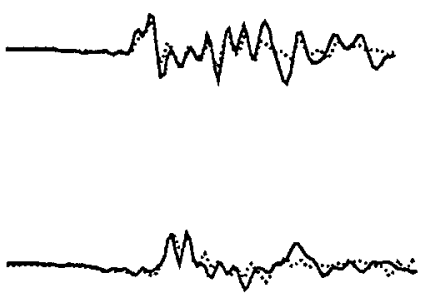

\begin{tabular}{llll}
\hline 0. & 5. & 10. & 15.
\end{tabular}

0. 5. 10. 15.20.
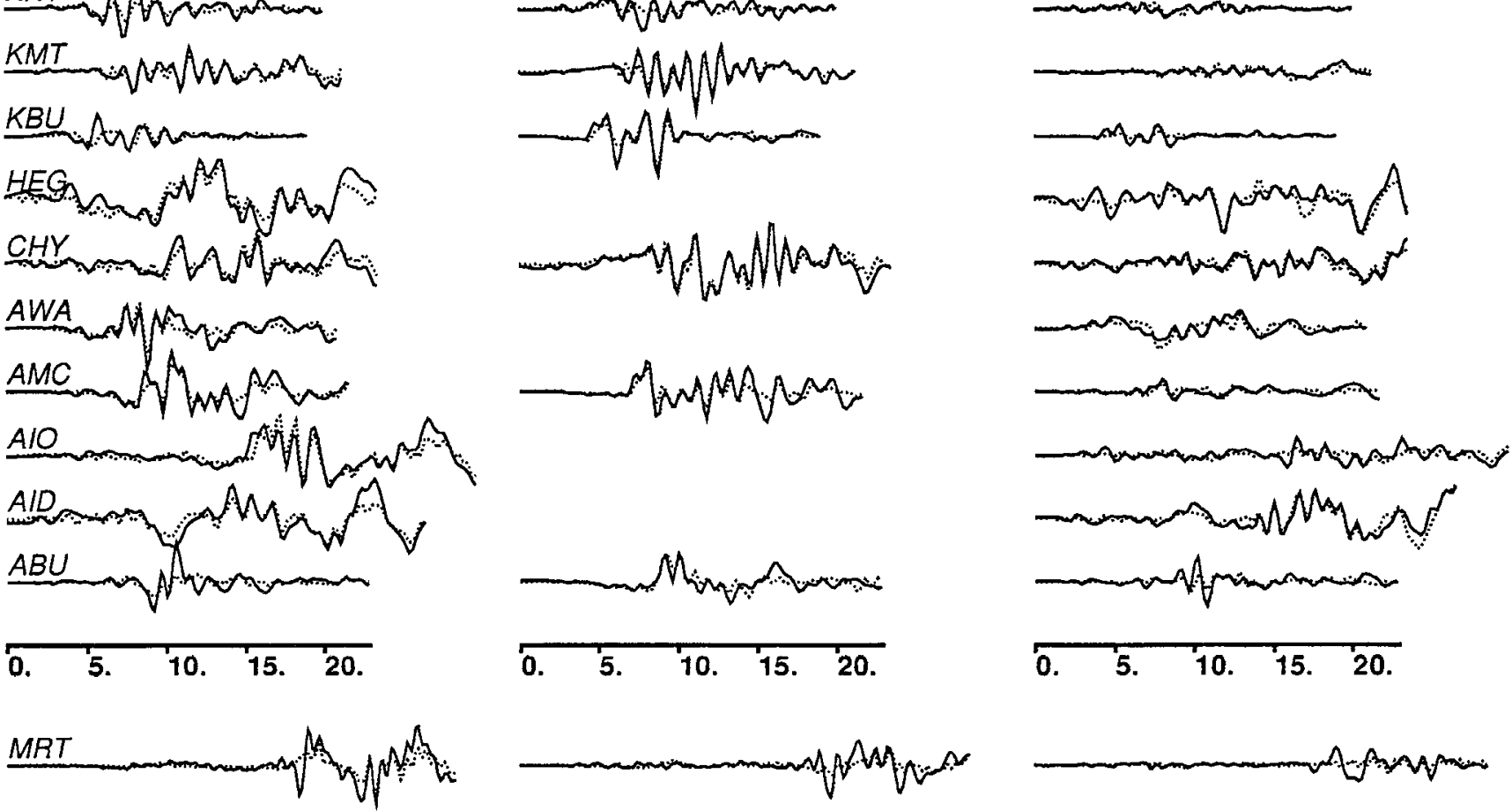

0. 5. 10. 15.20 .

0. 5. 10. 15. 20.

0. 5. 10. 15.20.

0. 5. 10.15 .20 .

Figure 10. Observed velocity waveforms (solid lines) and synthetics (dotted lines). 


\section{Contribution of Each Segment to Waveforms}

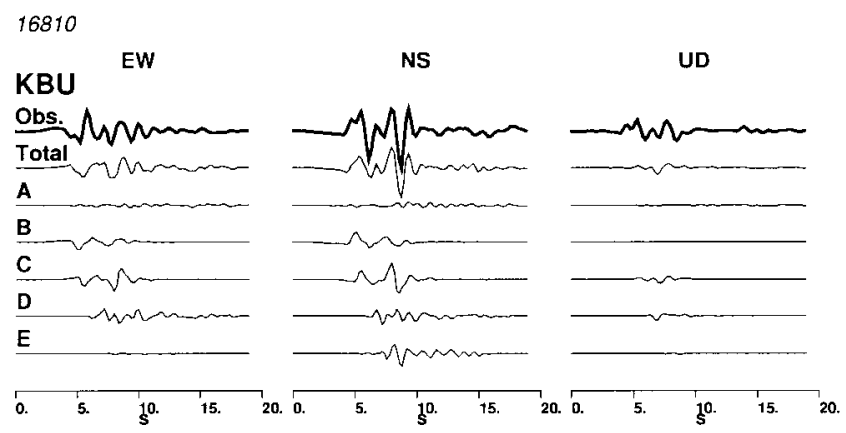

Figure 11. Observed (bold line) and synthetic (thin line) waveforms at KBU station. From the top: observed, synthetics for all 5 segments (ABCDE), and synthetics from segment A, B, C, D, and E.

\section{Inversion Results}

\section{Rupture Process for the Branching Fault Model}

Six different source models that use identical fault models, data sets, Green's functions, and rake angle variation constraints with different smoothing strengths are shown in Figure 8. A $\lambda$ value of 0.05 gave the smallest ABIC values among the inversions performed. So this was adopted as the source model. The misfit value increases markedly when $\lambda$ exceeds 0.05 , and the total moment release varies greatly due to the smoothing strength. Because the total-moment release varies with the amount of destructive interference suppressed by the smoothing constraint, and the total moment release values inverted for a large number of model parameters do not have high reliability.

The time progression for inverted rupture and the waveforms calculated for the ABCDE fault model when the ABIC value is smallest are shown in Figures 9 and 10. As in previous source inversion studies (Horikawa et al., 1996; Ide et al., 1996; Sekiguchi et al., 1996b; Wald, 1996; Yoshida and Koketsu, 1996), rupture progressed upward on the Awaji side and went into the deeper part on the Kobe side. Spatial distribution is more complicated as compared with previous findings (Sekiguchi et al., 1996b) perhaps because velocity waveforms and smaller grid spacing were used in the inversion. The three areas that had a relatively large moment release (subevents) were confirmed on segments A, B, and C in agreement with a previous report (Sekiguchi et al., 1996b). We found a subevent smaller than those three at the bottom of segment E. Significant contribution (remarkable phase that contributes to marked variance reduction) of segment $\mathrm{E}$ is seen only at stations near this segment, the second pulse in the waveforms being strengthened by the waves from the slip on segment E (Fig. 11). This kind of slip that appears at the very edge of an assumed fault plane often is suspected to be caused by random noise contained in the data, errors in Green's functions due to misestimation of shallow-velocity structures, or the need for extension of the model-fault plane. To examine its reliability, we performed
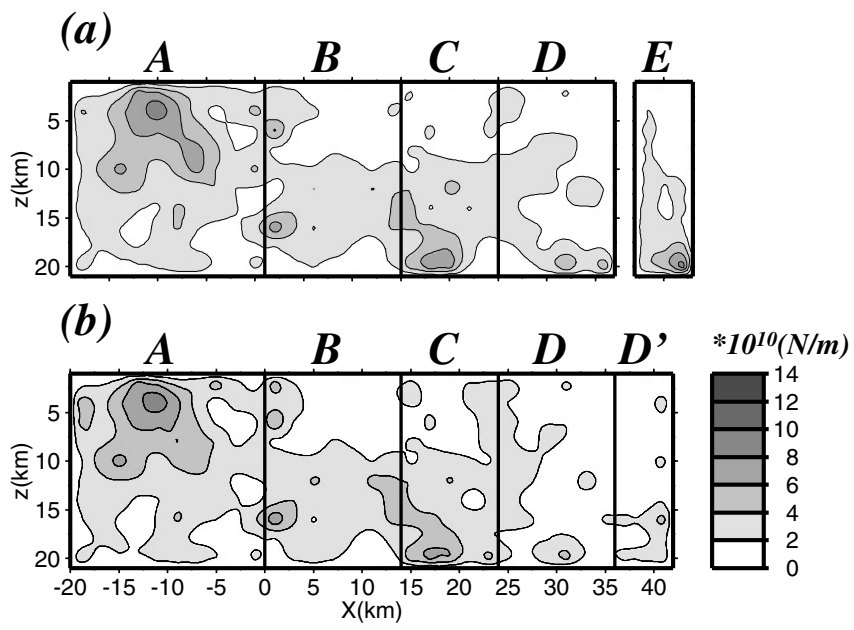

Figure 12. Final moment release distribution (a) for the ABCDE fault model with segments A, B, C, $\mathrm{D}$, and $\mathrm{E}$, and (b) for the $\mathrm{ABCDD}^{\prime}$ fault model.

another waveform inversion with the $\mathrm{ABCDD}^{\prime}$ model and made numerical resolution checks (see subsegment sections). The UD components of synthesized waveforms at stations near the fault are very small compared to the observed records. We considered the following reasons: the model fault planes are assumed by several planar, nearly vertical surfaces, and the slips on the fault planes are dominant in strike slip component. Because the angle formed by the fault plane and a line between a point on the fault planes and a nearby station generally is very small, the synthetics for those stations become dominant in the horizontal component. In contrast, real fault planes have not flat but rough and/or curved surfaces and should generate more UD component waves than the model fault. Small-scale heterogeneity of the crust, which is not considered in the theoretical Green's function calculation, also may give more UD components.

\section{Rupture Process for a Fault Model without Branching}

Waveform inversion was performed with the ABCDD' model (without the Okamoto fault) (Fig. 11), the source model with the minimum ABIC value was obtained, and results were compared with those of the ABCDE model. The final moment release distribution for this fault model is shown in Figure 12b. The overall rupture distribution characteristics are similar. No large moment releases were seen in the northeastern part of the fault. Variance reduction was slightly higher (2\%), and the ABIC value was smaller for the ABCDE model as compared with the ABCDD' model. Variance reduction was much higher when branching was assumed at stations near the branch.

\section{Numerical Resolution Check}

Examination of the Effect of Random

Noise on Inversion Results

We examined whether random noise in the data would generate a ghost subevent on the Okamoto fault. Again, a 

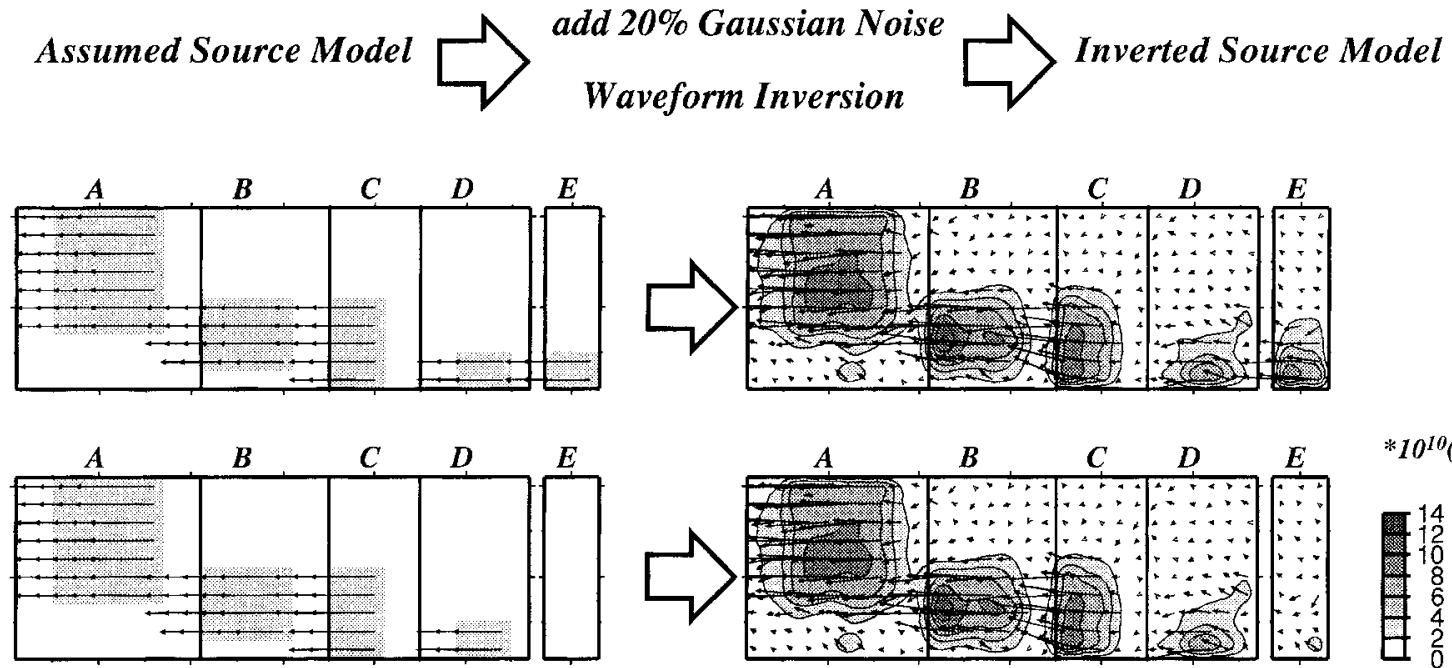

$* 10^{10}(N / m)$

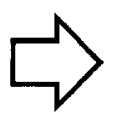

\section{$20 \%$ Gaussian Noise cannot generate \\ a Ghost Subevent on the Branched Fault}

Figure 13. Distribution of the final moment release and slip of the assumed (left) and inverted (right) source models for the resolution check used to examine the effect of random noise on the waveform inversion result. In case 1 (upper), five subevents are assumed, and in case 2 , four subevents are assumed.

\section{use Time-Shifted Green's functions corresponding to Misestimation of the Velocity Structure (SD 3.5\%)}
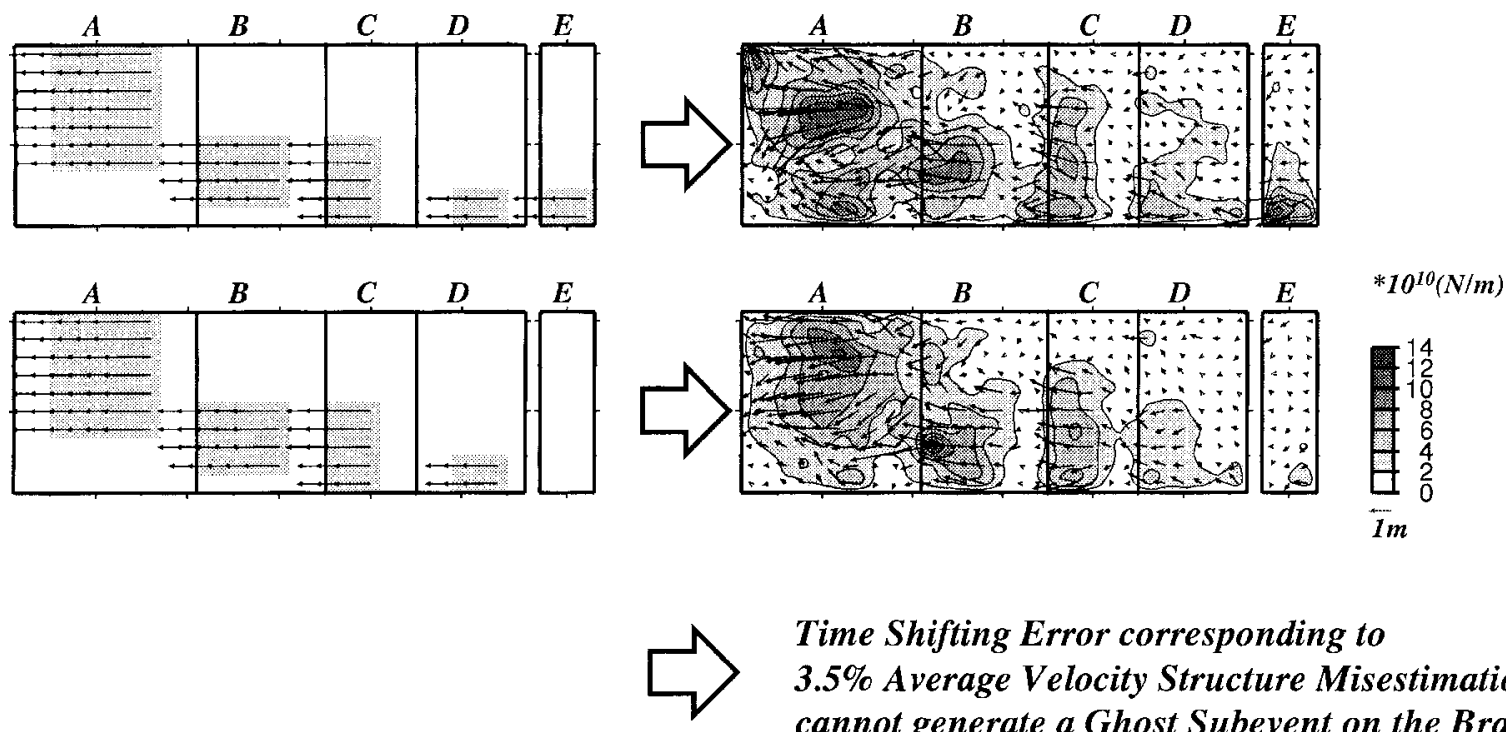

Time Shifting Error corresponding to 3.5\% Average Velocity Structure Misestimation cannot generate a Ghost Subevent on the Branched Fault

Figure 14. Distributions of final-moment release and slip of the assumed (left) and inverted (right) source models for the resolution check on the effect of misestimation of the velocity structure on the waveform inversion result. In case 1 (upper), five subevents are assumed, and in case 2, four subevents. 


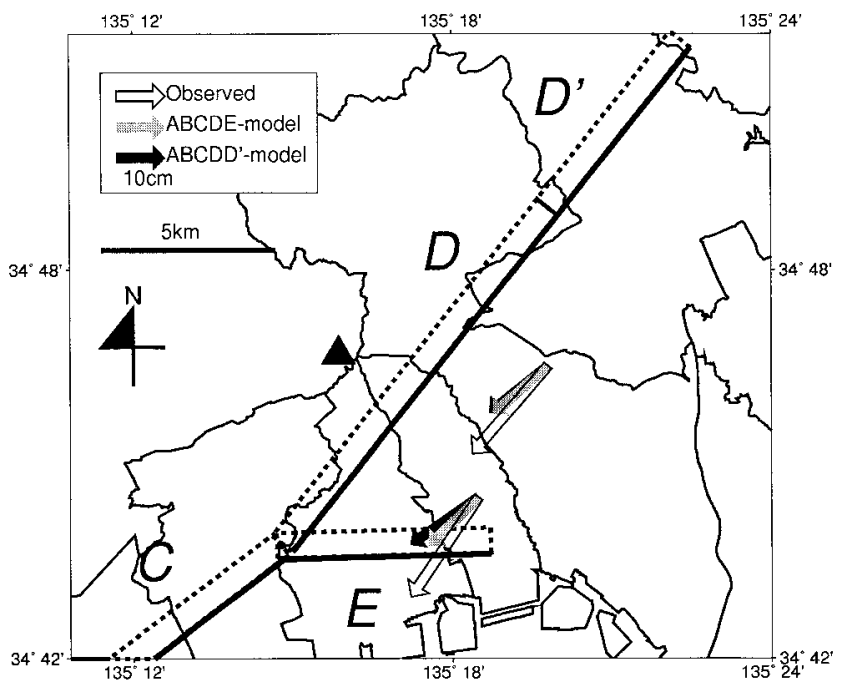

Figure 15. Relative static displacement vectors between the leveling observation stations near the branching fault. The station on the northwest side of segment D segment is fixed, whereas the relative static displacements of the two stations on the southeast side are calculated. Open arrows indicate the observed static displacements, gray ones synthetics from the ABCDE-model, and black ones synthetics from the $\mathrm{ABCDD}$ '-model.

homogeneous pure strike slip was assumed on areas surrounded by the bold line (Fig. 13), and target waveforms were generated for two conditions. In case 1, five subevents were assumed, and in case 2 , four subevents. Gaussian noise was added to the target waveforms. The standard deviation of noise was $20 \%$ of the peak amplitude of the target waveforms. The noise level was deduced from the misfitting of the target and inverted waveforms for available aftershocks, using the velocity structure models in the present waveform inversion (Bouchon et al., 1998). In this test, the smoothing strength parameter was fixed at the same value found as the most appropriate value in the inversion of the real data. Because of noise and smoothing constraints in the waveform inversion, moment release appears even beyond the assumed subevent areas, and especially around the subevents. In case 1 , an assumed subevent at the bottom of the Okamoto fault was recovered. In case 2 , no remarkable ghost subevent was found there. This means that a subevent like the one obtained at the bottom of the Okamoto fault in the real-data inversion can not be generated, even assuming there is as much as $20 \%$ random noise.

Examination of Misestimation of the Velocity Structure on Inversion Results

Next, we examined whether the effect of misestimating the velocity structure can generate a ghost subevent on the Okamoto fault. Such misestimation is thought to induce systematic errors in the Green's functions for the inversion. As explained earlier, the velocity-structure models were tuned by trial and error to obtain the $P$-arrival, $S$-arrival, or $P-S$ time in the observations. Tuning, however, was not complete. Moreover, the lateral heterogeneity of the velocity structure, which was not considered in our calculations, generates errors in the Green's functions. These errors are characterized by amplitude and phase misestimation, and arrivaltime differences, the latter being more severe in the waveform inversion. The average error of the $S$-arrival times of the Green's functions, calculated between the hypocenter subfault and observation stations for which absolute time information is available, was about $3.5 \%$ of the $S$-wave travel time. It turns out that in our study the average seismic wave velocity in the medium has about $3.5 \%$ error. A set of element waveforms was generated, and time shifts were given corresponding to the misestimation of the average velocity that had a deviation range that followed a Gaussian distribution with a standard deviation of $3.5 \%$ of the average velocity of each station's structure model. Of course, all the element waveforms shifted in time for the structure model misestimation and were time-shifted again so that the $S$ arrival from the hypocenter subfault would meet the $\mathrm{S}$-arrival of the observation, a usual procedure in waveform inversion. Target waveforms were calculated assuming five subevents in case 1 and four in case 2, using no time-shifted element waveforms (Fig. 14).

Recovery of the moment-release distribution was not good, even with only $3.5 \%$ misestimation of the average seismic-wave velocity, indicative that misestimation of the velocity structure causes large errors in the resulting solution and of the importance of constructing reliable velocity structure models for waveform inversion. Even so, an assumed subevent at the bottom of the Okamoto fault was recovered in case 1 , but not in case 2 . This means that a subevent like that we obtained at the bottom of the Okamoto fault in the real data inversion can not be generated by $3.5 \%$ misestimation of the average velocity of the seismic wave in the crust.

\section{Contribution of the Branching Segment to Static Displacement}

Static displacements were computed at leveling observation stations near the branching fault to determine the contribution of the branching fault (Fig. 15), using the method of Hernandez et al. (1997). The same lateral homogeneous velocity structure as for the KBU station in the waveform inversion was assumed, and the static on the synthetics far after the arrival of the slowest waves was measured. As the leveling observation stations are close to the model fault planes, the Green's functions from distributed point sources on a subfault too close to a station to be represented by a single-point source were calculated. The density of the distributed point sources on the subfault was determined from the relative distance between the subfault and the station. Clearly, the direction of the synthetic-static displacement at the southernmost station of the two better agrees with that 


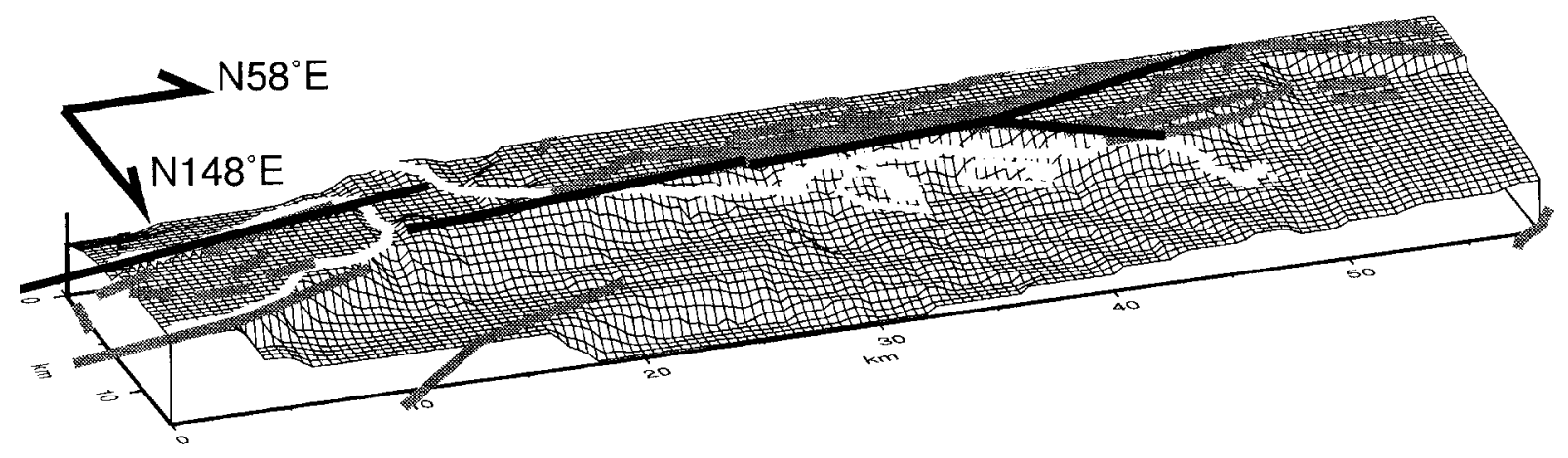

Figure 16. Bird's eye view of the sediment-bedrock interface topography of the model space for 3D FDM wave-field modeling (Iwata et al., 1999). The space stretches $58 \mathrm{~km}$ in the direction $\mathrm{N} 58^{\circ} \mathrm{E}, 13.6 \mathrm{~km}$ in the direction of $\mathrm{N} 148^{\circ} \mathrm{E}$, and $23 \mathrm{~km}$ in deep.

Table 4

Model Parameters of an Underground Structure for 3D Simulation (after Iwata et al., 1999)

\begin{tabular}{lccccc}
\hline & $V_{\mathrm{P}}(\mathrm{km} / \mathrm{sec})$ & $V_{\mathrm{S}}(\mathrm{km} / \mathrm{sec})$ & $\rho\left(\mathrm{g} / \mathrm{cm}^{3}\right)$ & $Q_{\mathrm{P}}=Q_{\mathrm{s}}$ & Depth $(\mathrm{km})$ \\
\hline Sediment 1 & 2.0 & 0.6 & 2.1 & 80 & Irregular \\
Sediment 2 & 2.2 & 1.1 & 2.1 & 80 & Irregular \\
1st rock & 5.5 & 3.2 & 2.4 & 300 & 4.0 \\
2nd rock & 6.0 & 3.5 & 2.7 & 400 & 17.8 \\
Half space & 6.7 & 3.9 & 2.8 & 500 & - \\
\hline
\end{tabular}

of the observation of the slip distribution of the ABCDE model, rather than the $\mathrm{ABCDD}^{\prime}$ model is assumed. At the northernmost station the difference caused by the two source models is negligible.

\section{Contribution of the Branching Segment to the Near-Source Ground Motion}

Near-source ground motion was simulated using 3-D FDM (Pitarka et al., 1998) to gauge the effect of slip on the branched fault (Iwata et al., 1999). The heterogeneous structure model was selected based on the results of extensive reflection surveys (e.g., Huzita, 1996) made after this earthquake and on findings of Kagawa et al. (1993, 1998). A bird's eye view of the sediment-bedrock-interface topography in the model space is shown in Fig. 16. The model parameters of the underground structure are given in Table 4. The fourth and bottom windows of Figure 17 (after Iwata et al., 1999, but recalculated using the source model of the present study) respectively show the distribution of maximum horizontal ground velocity when whole moment release (inside the model space) is introduced and when moment release on only the branched fault is assumed. Characteristic distribution of ground motion in the nearsource region, indicated by the damage distribution (Fig. 1), is well reproduced by the modeling of both the source process and wave propagation in the realistic $3 \mathrm{D}$ velocity struc-
Max. Horizontal Vel. Distribution $(0.1-1.0 \mathrm{~Hz})$
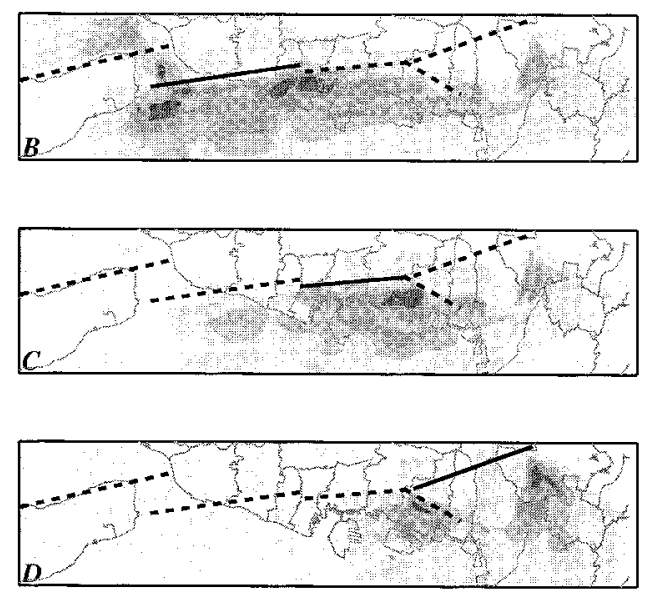

$(\mathrm{cm} / \mathrm{sec})$
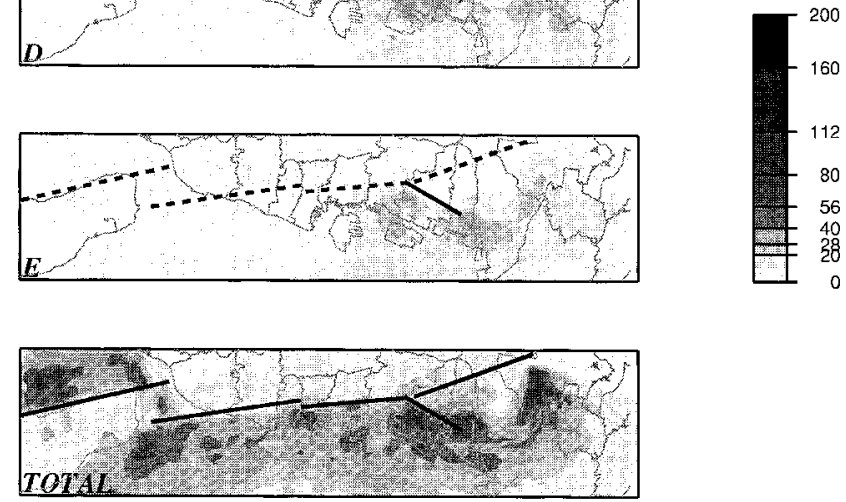

Figure 17. Distribution of the maximum-horizontal velocity from each segment of the source (after Iwata et al., 1999, but recalculated using the source model of the present study.) From top to bottom: distributions of maximum horizontal velocities caused by slip on Segments B, C, D, E and on the entire source area.

ture. The slip on the branched fault affected the ground motion in the eastern part of Kobe (Nada and Higashi-Nada wards), Ashiya, and Nishinomiya cities. But its contribution was not dominant, even in those regions. 


\section{Conclusions}

Waveform inversion for the source process of the 1995 Hyogo-ken Nanbu earthquake was performed, focusing on the fault geometry and slip distribution at rupture termination. Fault branching in the northeastern part of the faultplane model was assumed because it was suggested by static displacements (Murakami et al., 1995; Hashimoto et al., 1996) and damage extension east of Kobe (the Ashiya and Nishinomiya areas). Three main subevents were recovered as in a previous study (Sekiguchi et al., 1996b). Moreover, a subevent smaller than these three subevents was found at the bottom of the assumed branching E segment. A significant contribution of the E segment was seen only at stations near this segment at which the second pulse in the waveforms was strengthened by waves from slips on the $\mathrm{E}$ segment. Relatively large slips were found in the deep part of the branch. Total-variance reduction was larger and the ABIC value was smaller when this branch was assumed, which is indicative of the superiority of the branching fault model. Resolution checks showed that the slip on the branched segment was caused neither by the random noise contained in the data nor by synthetic errors in the Green's functions due to misestimation of shallow-velocity structures. Slip distribution obtained with the ABCDE model (with the branch) produced a synthetic-static-displacement vector that better agreed with that of the actual record at the leveling observation station closest to the branching fault than did the slip distribution of $\mathrm{ABCDD}^{\prime}$ model (without the branch).

We conclude that a scenario in which there was the possibility that the causative fault branched and rupture advanced to the bottom of the Okamoto fault should be the preferred interpretation for this earthquake. We carefully eliminated records contaminated by strong-diffraction waves generated by the 3D bedrock topography near the basin's edge, and after obtaining the inversion result, ruled out the possibility that the result was caused by random noise or the misestimation of the shallow-velocity structure.

This finding agrees with Koketsu's (1998) report. He performed joint inversion of near- and far-field waveforms and geodetic data using fault models with and without the Okamoto fault branch (referred to as the Ashiya fault in his analysis) and obtained slightly better fitting to the data when he used the branching model.

As briefly noted in the introduction, the static displacements and the SAR interferograms around the Okamoto fault indicate the possibility of dislocation on that fault. No strong, conclusive evidence has been found, but there is much evidence providing positive support for rupture branching in the northeastern part of the source fault.

The fact that earthquake termination with fault branching was found using the waveform inversion of strong ground motion records supports the idea of a geometrical barrier suggested by geological observations (e.g., King, 1986; Nakata et al., 1998). The concept of such a barrier is expected to provide useful information for predicting in advance the source areas of future earthquakes.

The effect of slip on the branched fault has been shown in a near-source ground-motion simulation using the 3D FDM (Iwata et al., 1999). The characteristic distribution of ground motion in the near-source region, indicated by the damage distribution, is well reproduced by the modeling of both the source process and wave propagation in the realistic $3 \mathrm{D}$ velocity structure. The slip on the branched fault affected the ground motion in eastern Kobe (Nada and Higashi-Nada wards), Ashiya, and Nishinomiya, but its contribution was not dominant, even in those regions, being about 30 to $50 \%$ the maximum velocity at 0.1 to $1.0 \mathrm{~Hz}$.

\section{Acknowledgments}

We thank the organizations who provided the recordings: the Committee of Earthquake Observation and Research in the Kansai Area (CEORKA); Japan Meteorological Agency (JMA); Kansai Electric Power Co. Inc.; Port and Harbor Research Institute; Research Center of Earthquake Prediction of Disaster Prevention Research Institute, Kyoto University (RCEP of DPRI, Kyoto Univ.); Research Reactor Institute, Kyoto Univ. (RRI, Kyoto Univ.); Public Works Research Institute (Public Works Research Institute, 1995); Kobe City; Sekisui House Co. Inc.; Matsumuragumi Co. Inc.; and the Railway Technical Research Institute (Nakamura et al., 1996) (serial no. 032). We also are grateful to Takao Kagawa for providing the restored recordings for the KBU and MOT stations, Olivier Coutant who originally coded the program used to calculate Green's functions for layered media, Arben Pitarka for his 3D finite-difference code and instruction on its use, and Francisco J. Sanchez-Sesma, Hiroshi Kawase, and Andreas Rietbrock for their helpful advice. GMT (Genetic Mapping Tools, Version 3.0, Wessel and Smith, 1991) was used to make the figures. The discussion in this article was significantly improved by the efforts of the associate editor, David Wald, and two anonymous referees. This study was partially supported by Grant-In-Aide for Scientific Research, No. 08248111 and No. 11209201, from the Ministry of Education, Science, Sports, and Culture, Japan.

\section{References}

Akaike, H. (1980). Likelihood and the Bayes procedure, in Bayesian Statics, J. M. Bernardo, M. H. DeGroot, D. V. Lindley, and A. F. M. Smith (Editors), University Press, Valencia, Spain, 143-166.

Aki, K., and P. G. Richards (1980). Quantitative Seismology, W. H. Freeman, San Francisco, 932 pp.

Awata, Y., and K. Mizuno (1998). Explanatory text of the strip map of the surface fault ruptures associated with the 1995 Hyogo-ken Nanbu earthquake, central Japan: The Nojima, Ogura and Nadagawa earthquake faults, Geological Survey of Japan, Tsukuba, Tectonic map series 12, $74 \mathrm{pp}$, scale 1:10,000, (in Japanese).

Bouchon, M. (1981). A simple method to calculate Green's function for elastic layered media, Bull. Seism. Soc. Am. 71, 959-971.

Bouchon, M., H. Sekiguchi, K. Irikura, and T. Iwata (1998). Some characteristics of the stress field of the 1995 Hyogo-ken Nanbu (Kobe) earthquake, J. Geophys. Res. 103, B10, 24271-24282.

Furumura, T., and K. Koketsu (1998). Specific distribution of ground motion during the 1995 Kobe earthquake and its generation mechanism, Geophys. Res. Lett. 25, 785-788.

Hartzell, S. H., and T. H. Heaton (1983). Inversion of strong ground motion and teleseismic waveform data for the fault rupture history of the 1979 Imperial Valley, California, earthquake, Bull. Seism. Soc. Am. 73, 1553-1583. 
Hashimoto, M., T. Sagiya, H. Tsuji, Y. Hatanaka, and T. Tada (1996). Coseismic displacements of the 1995 Kobe earthquake, J. Phys. Earth 44, 255-279.

Hernandez, B., F. Cotton, M. Campillo, and D. Massonnet (1997). A comparison between short term (co-seismic) and long term (one year) slip for the Landers earthquake: Measurements from strong motion and SAR interferometry, Geophys. Res. Lett. 24, 1579-1582.

Horikawa, H., K. Hirahara, Y. Umeda, M. Hashimoto, F. Kusano (1996). Simultaneous inversion of geodetic and strong motion data for the source process of the Hyogo-ken Nanbu, Japan, earthquake, J. Phys. Earth 44, 455-471.

Huzita, K. (1996). Survey results of active faults in the Osaka-Kobe area, Proc. 9th Seminar on Studying Active Faults: On the Deep Structure of the Osaka Bay Area, 1-10 (in Japanese).

Ide, S., M. Takeo, and Y. Yoshida (1996). Source process of the 1995 Kobe earthquake: Determination of spatio-temporal slip distribution by Bayesian modeling, Bull. Seism. Soc. Am. 86, 547-566.

Ishihara, M., S. Yoshikawa, M. Mitamura, K. Mizuno, and T. Hayashi (1991). Quaternary Geological Map of Osaka and Adjacent Areas, Kinki, Japan, scale 1:125,000, in Urban Kubota 30, Kubota Co. Ltd. (in Japanese).

Iwata, T., H. Sekiguchi, A. Pitarka, and K. Irikura (1999). Ground motion simulations in the Kobe area during the 1995 Hyogoken-Nanbu earthquake, in The Effects of Surface Geology on Seismic Motion, Irikura K., K. Kudo, H. Okada, and T. Sasatani (Editors), Vol. 3, BALKEMA, Rotterdam, 1295-1310.

Kagawa, T., S. Sawada, Y. Iwasaki, and A. Nanjo (1993). Modeling of the deep underground structures of the Osaka basin, Proc. 22th JSCE Earthq. Eng. Symp., 199-202 (in Japanese)

Kagawa, T., K. Irikura, and I. Yokoi (1996). Restoring clipped records of near-field strong ground motion during the 1995 Hyogo-ken Nanbu (Kobe), Japan, earthquake, J. Natural Disas. Sci. 18, No. 1, 43-57.

Kagawa, T., S. Sawada, Y. Iwasaki, and A. Nanjo (1998). S-wave velocity structure model of the Osaka sedimentary basin derived from microtremor array observations, J. Seism. Soc. Jpn (Zisin) 51, 31-40 (in Japanese).

Kame, N., and T. Yamashita (1999). A new light on arresting mechanism of dynamic earthquake faulting, Geophys. Res. Lett. 26, 1997-2000.

Kawase, H. (1996). The cause of the damage belt in Kobe: The basin-edgeinduced diffracted Rayleigh waves, Seism. Res. Lett. 67, 25-34.

Kawase, H., and S. Matsushima (1998). Strong motion simulation in Kobe during the Hyogo-ken Nanbu earthquake of 1995 based on a threedimensional basin structure, J. Struct. Constr. Eng., AIJ 514, 111118 (in Japanese).

Kennett, B. L. N., and N. J. Kerry (1979). Seismic waves in a stratified half-space, Geophys. J. R. Astr. Soc. 57, 557-583.

King, G. C. P. (1986). Speculations on the geometry of the initiation and termination process of earthquake rupture and its relation to morphology and geological structure, PAGEOPH 124, 3, 567-585.

Kobe City and Institute of Construction Engineering (1998). HanshinAwaji earthquake disaster, and geology and active faults in Kobe, Kobe City, Kobe (in Japanese).

Koketsu, K. (1998). An overview of the rupture process, Report on the Hanshin-Awaji Earthquake Disaster, Common Series 2, Maruzen, Tokyo, 168-175 (in Japanese).

Lawson, C. L., and R. J. Hanson (1974). Solving Least Square Problems, Prentice-Hall, Inc., New Jersey, 340 pp.

Motosaka, M., and M. Nagano (1996). Analysis of amplification characteristics of ground motions in Kobe City taking account of deep irregular underground structure: interpretation of heavily damaged belt zone during the 1995 Hyogo-ken Nanbu earthquake, J. Struct. Constr. Eng., AIJ 488, 39-48 (in Japanese).

Moya, C. A., and K. Irikura (1998). Seismic attenuation, kappa and site response in the Osaka area, Japan, in Strong Motion Seismology: Lesson from the 1995 Hyogo-ken Nanbu Earthquake, Irikura K., T. Iwata, and H. Sekiguchi (Editors), Disaster Prevention Research Institute, Kyoto University, Uji, 715-729.

Murakami, M., S. Fujiwara, and T. Saito (1995). Detection of crustal deformations associated with the 1995 Hyogoken-Nanbu earthquake by interferometric SAR, Current News of the Geophysical Survey Institute of Japan, Tsukuba, No. 83, 24-27 (in Japanese).

Nakamura, Y., F. Uehan, and H. Inoue (1996). Waveform and its analysis of the 1995 Hyogo-ken Nanbu earthquake (II), JR Earthquake Information No. 23d, Railway Technical Research Institute, Tokyo (in Japanese).

Nakata, T., K. Shimazaki, Y. Suzuki, and E. Tsukuda (1998). Fault branching and directivity of rupture propagation, J. Geography 107, 4, 512 528 (in Japanese).

Nemoto, H., H. Katao, E. Suzuki, Y. Yoshida, and K. Irikura (1996). The spreading of aftershocks area directly after the 1995 Hyogo-ken Nanbu earthquake, Programme and Abstracts of Seism. Soc. Japan 1996, No. 2 (in Japanese).

Nemoto, H., H. Negishi, and K. Irikura (1997). Re-examination of the hypocenter of the Hyogo-ken Nanbu earthquake, J. Seism. Soc. Japan, Zisin 50, 125-129 (in Japanese).

Ozawa, S., M. Murakami, S. Fujiwara, and M. Tobita (1997). Synthetic aperture radar interferogram of the 1995 Kobe earthquake and its geodetic inversion, Geophys. Res. Lett. 24, 2327-2330.

Pitarka, A., K. Irikura, T. Iwata, and H. Sekiguchi (1998). Three-dimensional simulation of the near-fault ground motion for the 1995 Hyogoken Nanbu (Kobe), Japan, earthquake, Bull. Seism. Soc. Am. 88, 428440.

Public Works Research Institute, Ministry of Construction (1995). StrongMotion Acceleration Records from Public Works in Japan (No. 21), Technical note of public works research institute 64, Public Works Research Institute, Ministry of Construction, Tsukuba, 265 pp.

Sekiguchi, H., K. Irikura, T. Iwata, Y. Kakehi, and M. Hoshiba (1996a). Determination of the location of faulting beneath Kobe during the 1995 Hyogo-ken Nanbu, Japan, earthquake from near-source particle motion, Geophys. Res. Lett. 23, 387-390.

Sekiguchi, H., K. Irikura, T. Iwata, Y. Kakehi and M. Hoshiba (1996b). Minute locating of fault planes and source process of the 1995 Hyogoken Nanbu, Japan, earthquake from the waveform inversion of strong ground motion, J. Phys. Earth 44, 473-487.

Wald, D. J. (1996). Slip history of the 1995 Kobe, Japan, earthquake determined from strong motion, teleseismic, and geodetic data, J. Phys. Earth 44, 489-503.

Wessel, P., and W. H. F. Smith (1995). New version of the Genetic Mapping Tools released, EOS Trans Amer. Geophys. U. 76, 441, 445446.

Yoshida, S., K. Koketsu, B. Shibazaki, T. Sagiya, and Y. Yoshida (1996). Joint inversion of near- and far-field waveforms and geodetic data for the rupture process of the 1995 Kobe earthquake, J. Phys. Earth 44, 437-454.

Yoshida, S. (1989). Waveform inversion using ABIC for the rupture process of the 1983 Hindu Kush earthquake, Phys. Earth Planet. Inter. 56, $389-405$.

Disaster Prevention Research Institute

Kyoto University

Kyoto, Japan

E-mail: haru@egmdpri01.dpri.kyoto-u.ac.jp

(H.S.)

Disaster Prevention Research Institute

Kyoto University

Kyoto, Japan

(K.I., T.I.)

Manuscript received 9 March 1999. 